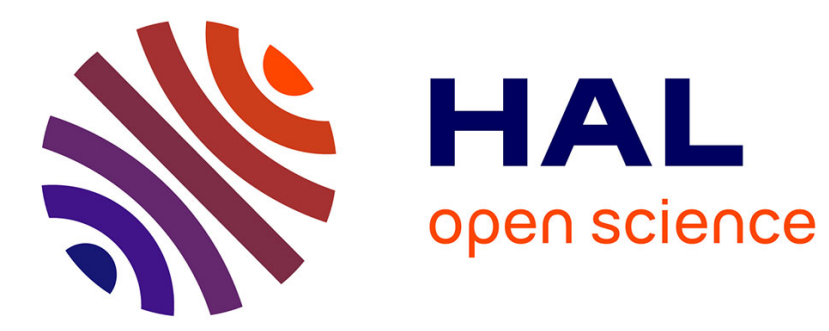

\title{
Asset bubbles and efficiency in a generalized two-sector model
}

\author{
Stefano Bosi, Cuong Le Van, Ngoc-Sang Pham
}

\section{To cite this version:}

Stefano Bosi, Cuong Le Van, Ngoc-Sang Pham. Asset bubbles and efficiency in a generalized twosector model. 2016. halshs-01316876

\section{HAL Id: halshs-01316876 \\ https://shs.hal.science/halshs-01316876}

Submitted on 17 May 2016

HAL is a multi-disciplinary open access archive for the deposit and dissemination of scientific research documents, whether they are published or not. The documents may come from teaching and research institutions in France or abroad, or from public or private research centers.
L'archive ouverte pluridisciplinaire HAL, est destinée au dépôt et à la diffusion de documents scientifiques de niveau recherche, publiés ou non, émanant des établissements d'enseignement et de recherche français ou étrangers, des laboratoires publics ou privés. 


\section{Documents de Travail du

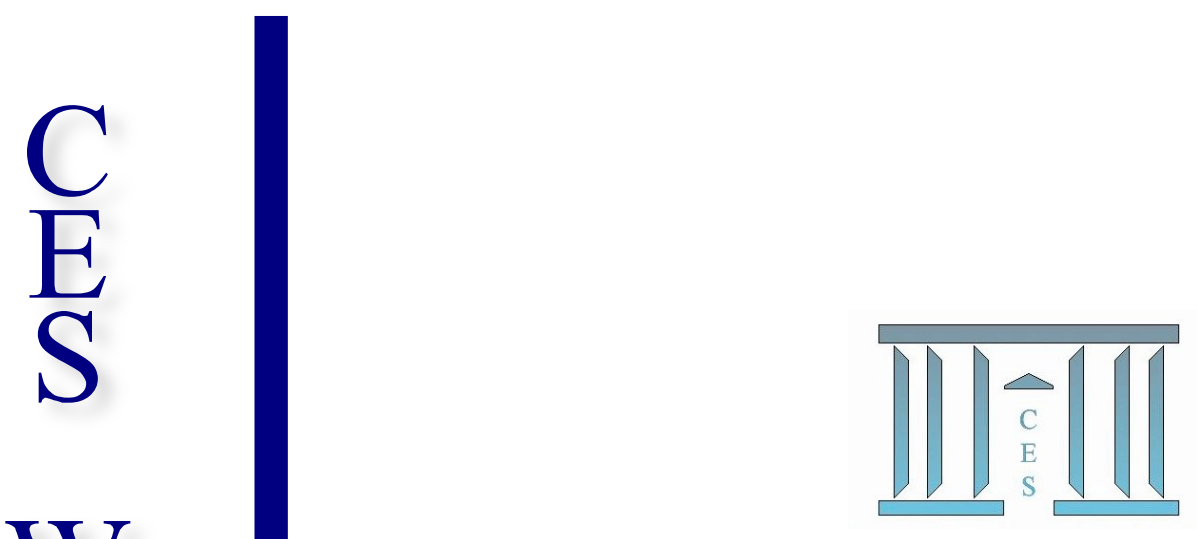

Asset bubbles and efficiency in a generalized two-sector model

Stefano Bosi, Cuong LE VAN, Ngoc-Sang PHAM

2016.29

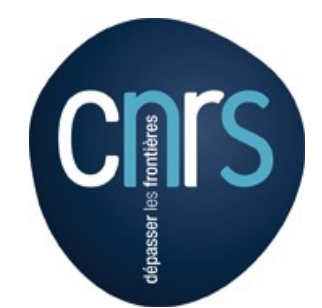




\title{
Asset bubbles and efficiency in a generalized two-sector model*
}

\author{
Stefano BOSI ${ }^{\dagger}$ Cuong LE VAN ${ }^{\ddagger} \quad$ Ngoc-Sang PHAM $^{\S}$
}

March 8, 2016

\begin{abstract}
We consider a multi-sector infinite-horizon general equilibrium model. Asset supply is endogenous. The issues of equilibrium existence, efficiency, and bubble emergence are addressed. We show how different assets give rise to very different rational bubbles. We also point out that efficient bubbly equilibria may exist.
\end{abstract}

Keywords: infinite-horizon, general equilibrium, aggregate good bubble, capital good bubble, efficiency.

JEL Classifications: D31, D91, E22, G10.

\section{Introduction}

The existence of rational bubbles in general equilibrium model is a challenging issue and thinking about this becomes indispensable to understand the real effects of financial markets. However, there are many kinds of bubble depending on the nature of asset and the definition of fundamental value.

A large strand of theoretical literature focuses on assets whose supply and dividends are exogenous. Tirole (1982) shows that asset bubbles fail to exist in dynamic general equilibrium models with rational expectations if traders have no endowments. Kocherlakota (1992) gives an example of bubble in an asset yielding no dividends with endowments growing at a larger rate than the rate of return and short-sales constraints of agents binding at infinitely many dates. A well-known result in this literature is the absence of bubble when the present value of aggregate outputs is finite $^{1}$ or agents' endogenous discount factors are equal. ${ }^{2}$ More recently, Becker et al. (2015) define the fundamental value of capital as the sum of discounted values

\footnotetext{
*This research was completed with the financial support of the Labex MME-DII.

${ }^{\dagger}$ EPEE, University of Evry. Email: stefano.bosi@univ-evry.fr.

${ }^{\ddagger}$ IPAG, CNRS, and Paris School of Economics. Email: Cuong.Le-Van@univ-paris1.fr.

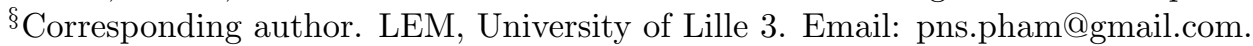

${ }^{1}$ Kocherlakota (1992), Santos and Woodford (1997) and Huang and Werner (2000) among others.

${ }^{2}$ Le Van and Pham (2014).
} 
of returns on capital and introduce the concept of capital bubble: this bubble exists when the price of capital strictly exceeds the fundamental value. ${ }^{3}$ Then, they prove the impossibility of capital bubbles in a Ramsey model.

Our motivation is to provide necessary and sufficient conditions under which bubbles arise, and to know whether any asset generates bubble. By the way, we explain why bubbles appear in a model and disappear in another, to bridge these different literatures and recover their disparate outcomes as particular cases of a general(ized) framework. It is natural to address the issues of equilibrium efficiency and linkage between bubbles and efficiency.

To this purpose, we build a generalized two-sector general equilibrium model with non-stationary production functions. Two goods are produced and exchanged: the aggregate good and the capital one. Both of them are processed to produce the aggregate good, which is the only one to be consumed. Moreover, the capital good is used to produce the capital good. The supply of both these goods is endogenous. Representative firms produce these goods, one firm per good. The economy is populated by a finite number of heterogeneous consumers. ${ }^{4}$

The model is general because allows us to study bubbles in capital and/or aggregate good in a unified framework.

Focus first on the meaning of bubble in the market of capital good. If a consumer invests by buying 1 unit of capital good at some date, then she expects to receive at the following date a so-called expected return on capital good, jointly with $1-\delta_{h}$ units of the same good, where $\delta_{h}$ is the depreciation rate of capital good. The expected return on capital good is the gain from this good, which fills the non-arbitrage condition: what we pay today to hold 1 unit of capital good is equal to what 1 unit of this good brings for us tomorrow. At equilibrium, we prove that the expected return on capital good equals the equilibrium return of capital good in the rental market.

The fundamental value of capital good is defined as the sum of discounted values of its expected returns (net of depreciation). We say that a bubble in the market of capital good exists if the equilibrium price of capital good exceeds its fundamental value. We recover bubbles in Tirole (1982), Kocherlakota (1992), Santos and Woodford (1997) as particular cases of capital good bubbles in our model (when the return is exogenous and the capital good is no longer produced). In particular, when the capital good is not used to produce, its returns are zero, and hence we recover the concept of pure bubble in Tirole (1985), Aoki et al. (2014), Hirano and Yanagawa $(2013) .^{5}$

Some results on the bubble in capital good deserve to be mentioned. We prove that this bubble exists if and only if the sum (over time) of ratios of capital good

\footnotetext{
${ }^{3}$ Ramsey (1928) and Solow (1956) call capital the amount of aggregate good used as productive input. In their one-sector growth model, the price of capital is the price of aggregate good.

${ }^{4}$ Becker and Tsyganov (2002) and Becker et al. (2015) are particular cases of our model: respectively when the aggregate good is only consumed and there is no capital good.

${ }^{5}$ The reader is referred to Miao (2014) for an introduction to bubbles in infinite-horizon models. Brunnermeier and Oehmke (2012) is a good survey on bubbles in OG models with asymmetric information or heterogeneous belief.
} 
return to capital good price is finite. This characterization has some consequences. (1) Bubbles in capital good bubbles exist only if the sum (over time) of the marginal productivities of capital good is finite. ${ }^{6}$ Therefore, when the technology in the capital good sector is stationary, bubbles in capital good are ruled out. (2) The supply of capital good is uniformly bounded from above if a bubble in capital good exists.

We show that bubbles in capital good are excluded if either the present value of profits is finite or the consumers' endogenous discount factors are the same from some date on. By consequence, there is no bubble in capital good if the agents' borrowing constraints are not binding from some dates. By the way, we extend the results in Kocherlakota (1992), Santos and Woodford (1997), Huang and Werner (2000) and Le Van and Pham (2014) to a capital good with endogenous supply. We also give some examples of bubble in capital good where the consumers' borrowing constraints bind at infinitely many dates and the TFP in the capital good sector tends to zero. We observe that a continuum of equilibria with bubble in capital good may emerge.

Focus now on the market of aggregate good and apply the same argument to define a bubble in this good. At some date, if a consumer invests by buying 1 unit of aggregate good, which is then rent for production, then she expect to receive at the following date a return (we call expected return on aggregate good), jointly with $1-\delta$ units of the same good, where $\delta$ is its depreciation rate of aggregate good. The fundamental value of aggregate good is defined as the sum of discounted values of its expected returns (net of depreciation). A bubble in the market of aggregate good is said to exist if the fundamental value is less than $1 .^{7}$

As for the capital good, the expected return on aggregate good is the gain from this good, which fills the non-arbitrage condition: what we pay today to hold 1 unit of aggregate good is equal to what 1 unit of this good brings for us tomorrow. However, differently from the capital good, the expected return on the aggregate good may differ from its equilibrium return; this may happen when the quantity of aggregate good used for production is null. For this reason, our definition of bubbles is more general than that in Becker et al. (2015). ${ }^{8}$

The nature of bubbles in aggregate good is also explored. These bubbles exist if and only if the sum (over time) of expected returns on aggregate good is finite (so-called low interest rates condition). The intuition behind is straightforward: the bubbly component, that is the difference between the price of aggregate good and its fundamental value, decreases in the expected returns on aggregate good and, therefore the bubble may be positive if these returns are very low. As was the case with bubbles in capital good, bubbles in aggregate good fail to exist under a stationary technology and we recover the no-bubble result found by Becker et al. (2015). The novelty is that aggregate good bubbles may appear when technology is not stationary.

Our generalized framework allows us to compare both these categories of bubbles and clarify, once for all, their nature. By means of examples, we show that a bubble

\footnotetext{
${ }^{6}$ Notice that the marginal productivity of capital good may be strictly less than its return.

${ }^{7} 1$ is the price of aggregate good since it is the numéraire.

${ }^{8}$ In Becker et al. (2015), the expected return on the aggregate good always equals the return in the rental market.
} 
in aggregate good may exist even if (1) the present value of output is finite, (2) all consumers are identical, (3) borrowing constraints of consumers are never binding. These surprising results are new and come from a structural difference between the two kinds of goods: the aggregate one is not only consumed but also processed in production, while the capital good is only used to produce. The following table sums up these findings.

\begin{tabular}{|l|l|l|}
\hline Statement & Capital good & Aggregate good \\
\hline No bubble if the present value of profits is finite & holds & may fail \\
\hline No bubble if there is one consumer & holds & may fail \\
\hline No bubble if borrowing constraints are not binding & holds & may fail \\
\hline
\end{tabular}

Interestingly, equilibrium bubbles in capital and aggregate good are not incompatible. Of course, in some cases, only one of these bubbles or no bubble at all exists.

We also give an example of one-sector economy (without capital good) experiencing a no-trade equilibrium with a bubble in the aggregate good. Interestingly, the returns on aggregate good in the rental market are zero at any date but its expected returns are always strictly positive. By the way, the fundamental value of aggregate good is strictly positive even when its returns are zero. This suggests that we should consider the expected returns, not equilibrium returns, to define the fundamental value. In this example, the existence of aggregate good bubble depends on the dynamics of consumers' wealth.

Interestingly too, bubbles and equilibrium efficiency are not incompatible. The last part of the paper tackles this issue. An intertemporal equilibrium is efficient in sense of Malinvaud (1953) if its production plan is efficient. ${ }^{9}$ Given an equilibrium, we prove that, if the endogenous discount factors of all consumers are identical from some date on, then this equilibrium is efficient. By consequence, if the consumers' borrowing constraints are never binding, the equilibrium is efficient. Conversely, Becker et al. (2014) give an example of inefficient equilibrium where borrowing constraints are binding at infinitely many dates.

We eventually show that an equilibrium is efficient if the present value of profits is finite. In particular, when the production functions are constant returns to scale, firms make zero profit and, hence, every intertemporal equilibrium is efficient. We don't require any condition about convergence or boundedness of capital path as was the case in the previous literature. Moreover, our result holds in both oneand two-sector models. Our result is also related to Becker and Mitra (2012) where they prove that, in a one-sector model, a Ramsey equilibrium is efficient if the most patient household is not credit-constrained from some date on. However, their result is based on the fact that the consumption of each household is uniformly bounded from below. ${ }^{10}$

\footnotetext{
${ }^{9} \mathrm{~A}$ production plan is efficient if (1) it is feasible and (2) there is no other feasible production plan which improves the aggregate consumption.

${ }^{10}$ The constrained efficiency is another important concept. Constrained inefficiency occurs when there exists a welfare-improving feasible redistribution subject to constraints (these constraints depends on models). About the constrained efficiency in general equilibrium models with financial
} 
Surprisingly, equilibria may be both efficient and bubbly (in the aggregate good) in a one-sector model with such technologies. Indeed, under a linear technology $F_{t}(K)=a_{t} K$ with $\sum_{t>1} a_{t}<\infty$, bubbles in aggregate good occur. Moreover, as seen above, every equilibrium is efficient. This possible coexistence of efficiency and bubbles rests on non-mutually exclusive conditions: nature of bubbles (low interest rates) and nature of efficiency (distribution of capital across periods).

The rest of the paper is organized as follows. Section 2 presents a generalized twosector model. In section 3, we define the bubbles in aggregate and capital goods and we compare these concepts with other ones in the existing literature. Sections 4 and 5 study the nature of bubbles in aggregate and capital goods while Section 6 addresses their linkage. Section 7 treats the equilibrium efficiency. Section 8 concludes. All technical proofs are gathered in Appendices.

\section{A two-sector model}

In the spirit of Becker and Tsyganov (2002) and Becker et al. (2015), we consider a general equilibrium model with two sectors and infinite-lived heterogeneous agents. The first sector produces an aggregate good which is consumed or used to produce the aggregate good, while the second sector a capital good which is processed to produce both the aggregate and the capital good. Time is discrete and runs from $t=0$ to infinity. $p_{t}$ and $q_{t}$ will denote the prices of aggregate and capital goods at date $t$ respectively.

\subsection{Productions}

A representative firm produces an aggregate good by using the same good and a capital good. This firm rents $K_{t}$ units of aggregate good and $H_{t}^{c}$ units of capital good to produce $F_{t}\left(K_{t}, H_{t}^{c}\right)$ units of aggregate good. $F_{t}$ represents a (possibly) nonstationary technology. Profit maximization writes

$$
P\left(p_{t}, r_{c, t}, r_{h, t}\right): \quad \pi_{c, t}\left(p_{t}, r_{c, t}, r_{h, t}\right):=\max _{K_{t} \geq 0}\left[p_{t} F_{t}\left(K_{t}, H_{t}^{c}\right)-r_{t} K_{t}-r_{h, t} H_{t}^{c}\right]
$$

where $r_{t}$ (resp., $r_{h, t}$ ) denote the return of aggregate (resp., capital) good at date $t$.

Remark 1. Inputs are not required to be essential. In other words, the cases $F_{t}(H, 0)>0$ or $F_{t}(0, K)>0$, with $K>0, H>0$, are allowed.

In this sector, the production plan satisfies two first-order conditions:

$$
\begin{aligned}
& p_{t} \frac{\partial F_{t}}{\partial K}\left(K_{t}, H_{t}^{c}\right) \leq r_{t}, \text { with equality when } K_{t}>0 \\
& p_{t} \frac{\partial F_{t}}{\partial H}\left(K_{t}, H_{t}^{c}\right) \leq r_{h, t}, \text { with equality when } H_{t}^{c}>0
\end{aligned}
$$

asset, see Kehoe and Levine (1993), Alvarez and Jermann (2000) and Bloise and Reichlin (2011). About the constrained efficiency in neoclassical growth models, see Davila et al. (2012). 
In the capital good sector, another representative firm produces the capital good by using the same good. Formally, the firm decides the demand of capital good $K_{t}^{k}$ to maximize the profit.

$$
P\left(q_{t}, r_{h, t}\right): \quad \pi_{k, t}\left(q_{t}, r_{t}\right):=\max _{H_{t}^{k} \geq 0}\left[q_{t} G_{t}\left(H_{t}^{k}\right)-r_{h, t} H_{t}^{k}\right]
$$

where $G_{t}$ is a non-stationary production function.

In this sector, the production plan satisfies a single first-order condition:

$$
q_{t} G_{t}^{\prime}\left(H_{t}^{k}\right) \leq r_{h, t}, \text { with equality when } H_{t}^{k}>0
$$

For notational parsimony, we will write $\pi_{c, t}$ and $\pi_{k, t}$ instead of $\pi_{c, t}\left(p_{t}, r_{t}\right)$ and $\pi_{k, t}\left(q_{t}, r_{t}\right) . \pi_{t}:=\pi_{c, t}+\pi_{k, t}$ will denote the aggregate profit of both the sectors.

\subsection{Heterogeneous consumers}

We consider a set $I$ of $m$ of consumers. Any consumer is shareholder of firm $j . \theta_{j}^{i}$ denotes the exogenous share of firm $j \in\{c, k\}$ held by agent $i \in I$. Of course, $\theta_{j}^{i} \geq 0$ for any $i$ and $j$, and $\sum_{i \in I} \theta_{j}^{i}=1$.

The consumer $i$ buys $c_{i, t}$ units of aggregate good to consume at date $t$. She may invest by buying $k_{i, t+1}$ units of aggregate good, which is then rent by the aggregate good producer. At the next date, this amount (1) gives back for the consumer $r_{t+1} k_{i, t+1}$ in monetary terms at date $t+1$, (2) depreciates to $(1-\delta) k_{i, t+1}$ units of aggregate good at date $t+1$.

Consumers may also invest in capital good. At time $t$, the consumer $i$ buys $h_{i, t+1} \geq 0$ units of this good at a price $q_{t}$. The following period, she receives returns $r_{h, t+1} h_{i, t+1}$ and $\left(1-\delta_{h}\right) h_{i, t+1}$ depreciated units of capital good, where $\delta_{h}$ is the depreciation rate of capital good. $r:=\left(r_{t}, r_{h, t}\right)_{t \geq 0}$ denotes the sequence of returns on aggregate and capital goods.

The consumer $i$ maximizes an intertemporal utility function:

$$
P_{i}(p, q, r): \quad \max _{\left(c_{i, t}, k_{i, t+1}, h_{i, t+1}\right)_{t=0}^{\infty}} \sum_{t=0}^{\infty} \beta_{i}^{t} u_{i}\left(c_{i, t}\right)
$$

facing sequences of borrowing and budget contraints:

$$
\begin{gathered}
k_{i, t+1} \geq 0 \text { and } h_{i, t+1} \geq 0 \\
p_{t}\left(c_{i, t}+k_{i, t+1}\right)+q_{t} h_{i, t+1} \leq p_{t}(1-\delta) k_{i, t}+r_{t} k_{i, t}+q_{t}\left(1-\delta_{h}\right) h_{i, t}+r_{h, t} h_{i, t}+\pi_{i, t} \\
\beta_{i} \in(0,1) \text { captures the time preference of consumer } i, \text { while } u_{i} \text { and } \pi_{i, t}:= \\
\theta_{c, t}^{i} \pi_{c, t}+\theta_{k, t}^{i} \pi_{k, t} \text { denote her utility function and profit. The initial portfolio }\left(h_{i, 0}, k_{i, 0}\right)
\end{gathered}
$$
is given. 


\subsection{Definition of equilibrium}

Definition 1. A sequence of prices and quantities

$$
\left(\bar{p}_{t}, \bar{q}_{t}, \bar{r}_{t}, \bar{r}_{h, t},\left(\bar{c}_{i, t}, \bar{k}_{i, t+1}, \bar{h}_{i, t+1}\right)_{i \in I}, \bar{K}_{t}, \bar{H}_{t}, \bar{H}_{t}^{c}, \bar{H}_{t}^{k}\right)_{t \geq 0}
$$

is an equilibrium of the economy $\mathcal{E}=\left(\left(u_{i}, \beta_{i}, k_{i, 0}, h_{i, 0}, \theta_{i}\right)_{i \in I}, \delta, \delta_{h},\left(F_{t}, G_{t}\right)_{t \geq 0}\right)$ if the following conditions hold.

(i) Price positivity: $\bar{p}_{t}, \bar{r}_{t}, \bar{r}_{h, t}>0, \bar{q}_{t} \geq 0$ for any $t \geq 0$.

(ii) Market clearing:

$$
\begin{aligned}
& \text { aggregate good: } \sum_{i \in I}\left(\bar{c}_{i, t}+\bar{k}_{i, t+1}\right)=\sum_{i \in I}(1-\delta) \bar{k}_{i, t}+F_{t}\left(\bar{K}_{t}, \bar{H}_{t}^{c}\right) \\
& \text { capital good: } \sum_{i \in I} \bar{h}_{i, t+1} \leq\left(1-\delta_{h}\right) \sum_{i \in I} \bar{h}_{i, t}+G_{t}\left(\bar{H}_{t}^{k}\right) \\
& \bar{q}_{t}\left(\sum_{i \in I} \bar{h}_{i, t+1}-\left(1-\delta_{h}\right) \sum_{i \in I} \bar{h}_{i, t}-G_{t}\left(\bar{H}_{t}^{k}\right)\right)=0 \\
& \text { rental markets: } \bar{K}_{t}=\sum_{i \in I} \bar{k}_{i, t} \text { and } \bar{H}_{t}^{c}+\bar{H}_{t}^{k}=\sum_{i \in I} \bar{h}_{i, t} .
\end{aligned}
$$

for any $t \geq 0$.

(iii) Optimal consumption plans: $\left(\bar{c}_{i, t}, \bar{k}_{i, t+1}, \bar{h}_{i, t+1}\right)_{t \geq 0}^{\infty}$ is a solution to the problem $\left(P_{i}(\bar{p}, \bar{r})\right)$ for any $i$.

(iv) Optimal production plans: $\left(\bar{K}_{t}, \bar{H}_{t}^{c}\right)$ is a solution to the problem $P\left(\bar{p}_{t}, \bar{r}_{c, t}, \bar{r}_{k, t}\right)$ and $\left(\bar{H}_{t}^{k}\right)$ is a solution to the problem $P\left(\bar{q}_{t}, \bar{r}_{k, t}\right)$ for any $t \geq 0$.

Remark 2. The capital good can be also interpreted as human capital.

Inequalities $(4,5)$ allow us to prove the boundedness of feasible aggregate and capital good.

Lemma 1. Let $F, G$ be increasing and concave production functions with $F(0,0)=$ $G(0)=0$. Assume that (1) $F_{t}=a_{t} F$ for every $t$ where $a_{t} \in[\underline{a}, \bar{a}]$ with $\underline{a}, \bar{a} \in(0, \infty)$, and (2) $G_{t}=b_{t} G$ for every $t$ where $b_{t} \in[\underline{b}, \bar{b}]$ with $\underline{b}, \bar{b} \in(0, \infty)$.

If $0<\bar{b} G^{\prime}(\infty)<\delta_{h}$, then the capital good stock $\left(H_{t}\right)$ is uniformly bounded from above, that is there exists $\bar{H} \in(0, \infty)$ such that $H_{t} \leq \bar{H}$ for any $t$. Moreover, if

$$
0<\lim _{K \rightarrow \infty}\left[\bar{a} \frac{\partial F}{\partial K}(K, \bar{H})\right]<\delta
$$

then the aggregate good stock $\left(C_{t}+K_{t+1}\right)_{t}$ is uniformly bounded from above, that is there exists $\bar{K} \in(0, \infty)$ such that $C_{t}+K_{t+1} \leq \bar{K}$ for any $t$. 


\subsection{Finite-horizon economies}

We define a finite-horizon economy with a final date $T$ as an infinite-horizon economy with three additional conditions: (1) there are no activities from date $T+1$ on, (2) $k_{i, T+1}=h_{i, T+1}=0$ and (3) $q_{T}=0$. In this case, the last budget constraint of agent $i$ becomes

$$
p_{T} c_{i, T} \leq p_{T}(1-\delta) k_{i, T}+r_{T} k_{i, T}+r_{h, T} h_{i, T}+\pi_{i, T}
$$

The agent $i$ buys $k_{i, T}$ units of aggregate good and $h_{i, T}$ units of capital good at date $T-1$. At date $T$, the aggregate good depreciated to $(1-\delta) k_{i, T}$ units, while the capital good to $\left(1-\delta_{h}\right) h_{i, T}$ units. The value of aggregate good $p_{T}(1-\delta) k_{i, T}$ is paid back to this agent, but the price of capital good becomes zero as well as its value.

\subsection{Existence of equilibrium}

By slightly adapting the proof in Becker et al. (2015), Le Van and Pham (2015), it is possible to show that, under mild conditions, there exist an equilibrium with $\bar{q}_{t}>0$ for any $t$ in the infinite-horizon economy and an equilibrium with $\bar{q}_{t}>0$ for any $t \leq T-1$ in the $T$-horizon economy. ${ }^{11}$ In the rest of the paper, we will focus on equilibria in infinite-horizon economies with $\bar{q}_{t}>0$ and

$$
\sum_{i \in I} \bar{h}_{i, t+1}=\left(1-\delta_{h}\right) \sum_{i \in I} \bar{h}_{i, t}+G_{t}\left(\bar{H}_{t}^{k}\right)
$$

\subsection{Particular cases}

Our general model encompasses some prominent cases of theoretical literature.

1. One-sector model. Becker et al. (2015), Bosi et al. (2014) are particular cases of our model when there is no capital good.

2. Lucas' tree. Another case of interest is the model with no depreciation $\left(\delta_{h}=\right.$ $0)$ and no production of capital good $\left(G_{t}=0\right)$, and $F_{t}(K, H)=F(K)+b_{t} H$. The supply of capital good becomes exogenous and reduces to the initial supply $\left(H_{0}:=\sum_{i} h_{i, 0}\right)$. The structure of capital good reduces to a Lucas' tree (Lucas, 1978) or stock (Kocherlakota, 1992).

3. Two-sector economy à la Becker and Tsyganov. Becker and Tsyganov (2002) is recovered with $k_{i, t}=0$ and $r_{t}=0$ for any $i$ and $t$. This holds when the aggregate good is no longer a productive good and depreciaiton is full $(\delta=1)$.

4. (Exogenously) pure consumption good. In the case where the depreciation is partial $(\delta<1)$ and the aggregate good is only consumed $\left(F_{t}(K, H)\right.$ no longer depends on $K$ and $\left.r_{t}=0\right),{ }^{12}$ the budget constraint of agent $i$ writes

$$
p_{t}\left(c_{i, t}+k_{i, t+1}\right)+q_{t} h_{i, t+1} \leq p_{t}(1-\delta) k_{i, t}+q_{t}\left(1-\delta_{h}\right) h_{i, t}+r_{h, t} h_{i, t}+\pi_{i, t}
$$

\footnotetext{
${ }^{11}$ The detailed proof is available upon request.

${ }^{12}$ Even when $r_{t}=0$, the aggregate $K_{t}$ may be strictly positive.
} 
The amount of consumption good purchased by an agent can be consumed today or stored for tomorrow. Storage is the way to transfer wealth over time, but one stored unit depreciates from a period to another to $(1-\delta)$ units.

5. Endogenously pure consumption good. Production may involve both the inputs (aggregate and capital good), but, at equilibrium, only the capital good is used to produce both the goods.

6. Macroeconomic perspective. Let $\left(p_{t}, q_{t}, r_{t}, r_{h, t},\left(c_{i, t}, k_{i, t+1}, h_{i, t+1}\right)_{i \in I}, K_{t}^{c}, H_{t}^{c}, H_{t}^{k}\right)_{t \geq 0}$ be an equilibrium and $K_{t}:=\sum_{i \in I} k_{i, t}, H_{t}:=\sum_{i \in I} h_{i, t}$ and $C_{t}:=\sum_{i \in I} c_{i, t}$. Agent $i$ diversifies her portfolio in $k_{i, t+1}$ units of aggregate good and $h_{i, t+1}$ units of capital good. The value of her total saving is given by $s_{i, t}:=p_{t} k_{i, t+1}+q_{t} h_{i, t+1}$, while the value of aggregate saving by $S_{t}:=\sum_{i \in I} s_{i, t}=p_{t} K_{t+1}+q_{t} H_{t+1}$. The value of gross investment at date $t$ writes

$$
\begin{aligned}
I_{t} & =p_{t} K_{t+1}+q_{t} H_{t+1}-p_{t}(1-\delta) K_{t}-q_{t}\left(1-\delta_{h}\right) H_{t} \\
& =p_{t} K_{t+1}-p_{t}(1-\delta) K_{t}+q_{t} G_{t}\left(H_{t}^{k}\right) .
\end{aligned}
$$

Note that $I_{t}$ may be negative. Market clearing conditions imply the following decomposition of aggregate output $p_{t} C_{t}+I_{t}=p_{t} F_{t}\left(K_{t}^{c}, H_{t}^{c}\right)+q_{t} G_{t}\left(H_{t}^{k}\right)$.

\subsection{Basic equilibrium properties}

We consider an equilibrium $\left(p_{t}, q_{t}, r_{t}, r_{h, t},\left(c_{i, t}, k_{i, t+1}, h_{i, t+1}\right)_{i \in I}, K_{t}, H_{t}, H_{t}^{c}, H_{t}^{k}\right)_{t \geq 0}$. Without loss of generality, we normalize the sequence of prices of aggregate good: $p_{t}=1$ for any $t$.

By using the argument in the proof of Theorem 1 of Kamihigashi (2002), we can prove the transversality condition at equilibrium.

Lemma 2. At equilibrium,

$$
\lim _{t \rightarrow \infty} \beta_{i}^{t} u_{i}^{\prime}\left(c_{i, t}\right) k_{i, t+1}=\lim _{t \rightarrow \infty} \beta_{i}^{t} u_{i}^{\prime}\left(c_{i, t}\right) q_{t} h_{i, t+1}=0
$$

for any agent $i$.

Lemma 2 is indispensable to prove the following characterization of equilibrium existence.

Lemma 3. A non-negative list $\left(p_{t}, q_{t}, r_{t}, r_{h, t},\left(c_{i, t}, k_{i, t+1}, h_{i, t+1}\right)_{i \in I}, K_{t}, H_{t}, H_{t}^{c}, H_{t}^{k}\right)_{t>0}$ with $q_{t}>0$ for any $t$ is an equilibrium if and only if the following conditions are satisfied.

1. $p_{t}, q_{t}, r_{t}, r_{h, t}>0$ for any $t$.

2. $p_{t}\left(c_{i, t}+k_{i, t+1}\right)+q_{t} h_{i, t+1}=p_{t}(1-\delta) k_{i, t}+r_{t} k_{i, t}+q_{t}\left(1-\delta_{h}\right) h_{i, t}+r_{h, t} h_{i, t}+\pi_{i, t}$ for any $i$ and $t$. 
3. Consumers' first-order conditions: There are positive sequences $\left(\lambda_{i, t}, \nu_{i, t}, \mu_{i, t}\right)_{i, t}$ such that

$$
\begin{aligned}
\beta_{i}^{t} u_{i}^{\prime}\left(c_{i, t}\right) & =\lambda_{i, t} \\
\lambda_{i, t} & \left.=\lambda_{i, t+1}\left(r_{t+1}+1-\delta\right)\right)+\nu_{i, t+1}, \quad \nu_{i, t+1} k_{i, t+1}=0 \\
\lambda_{i, t} q_{t} & =\lambda_{i, t+1}\left(r_{h, t+1}+q_{t+1}\left(1-\delta_{h}\right)\right)+\mu_{i, t+1}, \quad \mu_{i, t+1} h_{i, t+1}=0 .
\end{aligned}
$$

4. Transversality conditions: $\lim _{t \rightarrow \infty} \beta_{i}^{t} u_{i}^{\prime}\left(c_{i, t}\right) k_{i, t+1}=\lim _{t \rightarrow \infty} \beta_{i}^{t} u_{i}^{\prime}\left(c_{i, t}\right) q_{t} h_{i, t+1}=0$ for any $i$.

5. Optimality of production plans: Conditions (1, 2, 3) hold.

6. Market clearing conditions:

$$
\begin{aligned}
\sum_{i \in I}\left(c_{i, t}+k_{i, t+1}\right) & =\sum_{i \in I}(1-\delta) k_{i, t}+F_{t}\left(K_{t}, H_{t}^{c}\right) \\
\sum_{i \in I} h_{i, t+1} & =\left(1-\delta_{h}\right) \sum_{i \in I} h_{i, t}+G_{t}\left(H_{t}^{k}\right) \\
K_{t} & =\sum_{i \in I} k_{i, t}, \quad H_{t}^{c}+H_{t}^{k}=\sum_{i \in I} h_{i, t}
\end{aligned}
$$

Conditions (3) and (4) in Lemma 3 ensure the optimality of consumption plans $\left(c_{i, t}, k_{i, t+1}, h_{i, t+1}\right)$. The proof of Lemma 3 is left to the reader.

\section{8 (Expected) returns}

We denote by

$$
\gamma_{t}:=\max _{i \in\{1, \ldots, m\}} \frac{\beta_{i} u_{i}^{\prime}\left(c_{i, t}\right)}{u_{i}^{\prime}\left(c_{i, t-1}\right)}
$$

the discount factor of the economy from date $t$ to date $t+1$ and by $Q_{t}:=\prod_{s=1}^{t} \gamma_{s}$ the discount factor of the economy from date 0 to date $t$. By convention, we set also $Q_{0}:=1$. Asset pricing rests on these definitions.

Lemma 4 (asset-pricing for aggregate and capital goods). We have, for any $t \geq 0$,

$$
\begin{aligned}
q_{t} & =\gamma_{t+1}\left(r_{h, t+1}+\left(1-\delta_{h}\right) q_{t+1}\right) \\
1 & \geq \gamma_{t+1}\left(r_{t+1}+1-\delta\right), \text { with equality if } K_{t+1}>0
\end{aligned}
$$

Remark 3. $\beta_{i} u_{i}^{\prime}\left(c_{i, t+1}\right) / u_{i}^{\prime}\left(c_{i, t}\right)=\gamma_{t+1}$ if $k_{i, t+1}>0$ or $h_{i, t+1}>0$.

Definition 2. The expected return $\rho_{t}$ of aggregate good at date $t$ is defined by

$$
1=\gamma_{t}\left(\rho_{t}+1-\delta\right)
$$


The expected return on aggregate good is the gain from this good, which fills the non-arbitrage condition: what we pay today to hold 1 unit of aggregate good is equal to what 1 unit of this good brings for us tomorrow. According to (19), we have $\rho_{t} \geq r_{t}$ and equality holds if $K_{t}>0$. We also see that if the expected return on aggregate good is strictly higher than the equilibrium return in the rental market of this good, i.e., $\rho_{t}>r_{t}$, then $K_{t}=0$. Notice that $\rho_{t}>r_{t}$ may happen at equilibrium if the aggregate good plays a little role in production (for instance, when $F_{t}$ no longer depends on $K$ ). This matter will be investigated further in Section 5.2.

Definition 3. The expected return $\rho_{h, t}$ of aggregate good between date $t-1$ and date $t$ is defined by

$$
q_{t-1}=\gamma_{t}\left(\rho_{h, t}+\left(1-\delta_{h}\right) q_{t}\right)
$$

According to non-arbitrage condition (18), the expected return is equal to the equilibrium return in the rental market, i.e., $\rho_{h, t}=r_{h, t}$ for any $t \geq 1$. The economic intuition is simple: the capital good is a pure input and is not consumed, hence its aggregate supply at each date equals the sum of depreciated capital good from the previous date and output from the capital good sector (see (16)), and hence $H_{t}>0$. Thus, there exists at least one consumer who buys capital good. By consequence, the expected return equals the return at each period.

\section{Definitions of bubbles}

In this section, we provide formal definitions of bubbles in aggregate and capital goods and we compare these concepts with those in the existing literature. Recall that we normalize the sequence of prices of aggregate good: $p_{t}=1$ for any $t$.

\subsection{Definition of bubble in capital good}

The capital good is a long-lived asset whose price (in terms of aggregat good) at the initial date equals $q_{0}$. Agents buy the capital good at date 0 taking in account future returns.

1. At date 1 , one unit purchased at date 0 will bring $r_{h, 1}$ units of aggregate good and $1-\delta_{h}$ units of capital good. Agents' arbitrage gives rise to an equilibrium no-arbitrage condition: $q_{0}=r_{h, 1} Q_{1}+\left(1-\delta_{h}\right) q_{1} Q_{1}$.

2. At date 2, $1-\delta_{h}$ units of the capital good will bring $\left(1-\delta_{h}\right) r_{h, 2}$ units of aggregate good and $\left(1-\delta_{h}\right)^{2}$ units of capital good. The intertemporal noarbitrage condition becomes: $\left(1-\delta_{h}\right) q_{1} Q_{1}=\left(1-\delta_{h}\right) r_{h, 2} Q_{2}+\left(1-\delta_{h}\right)^{2} q_{2} Q_{2}$. 
Iterating the argument, we find a generalization over $T$ periods.

$$
\begin{aligned}
q_{0} & =\left(r_{h, 1}+\left(1-\delta_{h}\right) q_{1}\right) Q_{1}=r_{h, 1} Q_{1}+\left(1-\delta_{h}\right) q_{1} Q_{1} \\
& =r_{h, 1} Q_{1}+\left(1-\delta_{h}\right)\left(r_{h, 2}+\left(1-\delta_{h}\right) q_{2}\right) Q_{2}=r_{h, 1} Q_{1}+\left(1-\delta_{h}\right) r_{h, 2} Q_{2}+\left(1-\delta_{h}\right)^{2} q_{2} Q_{2} \\
& =\cdots \\
& =\sum_{t=1}^{T}\left[\left(1-\delta_{h}\right)^{t-1} r_{h, t} Q_{t}\right]+\left(1-\delta_{h}\right)^{T} q_{T} Q_{T}
\end{aligned}
$$

According to (22), what we pay (in terms of aggregate good) at initial date to buy 1 unit of capital good equals what we expect to receive in the future.

The fundamental value of capital good at date 0 is defined as the sum of discounted values of its returns (net of depreciation):

$$
F V_{k}:=\sum_{t \geq 1}\left(1-\delta_{h}\right)^{t-1} r_{h, t} Q_{t}
$$

Definition 4 (bubble in capital good). There is a bubble in capital good if the equilibrium price of capital good exceeds its fundamental value: $q_{0}>\sum_{t \geq 1}\left(1-\delta_{h}\right)^{t-1} r_{h, t} Q_{t}$, or, equivalently, $\lim _{t \rightarrow \infty}\left(1-\delta_{h}\right)^{T} q_{T} Q_{T}>0$.

One unit of capital good at the initial date will depreciate to $(1-\delta)^{t}$ units of the same good at date $t$. The discounted value of this quantity is $Q_{t} q_{t}(1-\delta)^{t}$. Therefore, bubble in capital good is interpreted as the discounted market value (at infinity) of one unit of capital good at initial date.

As above, we recover other bubble definitions in theoretical literature as particular cases of ours.

1. If the depreciation of capital good is null $\left(\delta_{h}=0\right)$, there is no production of capital good $\left(G_{t}=0\right)$ and $F_{t}(K, H)=F(K)+b_{t} H$, then we recover rational asset bubbles in Kocherlakota (1992), Santos and Woodford (1997) for the case where consumers cannot borrow. In particular, if we assume that $F_{t}(K, H)=$ $F(K)$, then $r_{h, t}=0$; in this case, its fundamental value is zero and the capital good becomes a pure bubble asset as in Tirole (1985).

2. If the depreciation of capital good is full $\left(\delta_{h}=1\right)$, there is no bubble. The equilibrium price of capital becomes $q_{0}=r_{h, 1} Q_{1}$. For this reason, we will consider only the case of partial depreciation $\left(\delta_{h}<1\right)$ in the sequel.

3. In the case of a $T$-horizon economy (Section 2.4), nobody buys the capital good at the end (date $T$ ). By consequence, we have $q_{T}=0$ and, according to (22):

$$
q_{0}=\sum_{t=1}^{T}\left(1-\delta_{h}\right)^{t-1} r_{h, t} Q_{t}
$$




\subsection{Definition of bubble in aggregate good}

In the spirit of Becker et al. (2015), the aggregate good can be viewed as a long-lived asset whose price (in terms of aggregate good) at initial date equals 1. As above, agents buy the aggregate good at date 0 expect as follows:

1. At date 1 , one unit (from date 0 ) of this good will bring $\rho_{1}$ units of aggregate good (as return) and $1-\delta$ units of the same asset (because of depreciation). A no-arbitrage condition holds at equilibrium: $1=\rho_{1} Q_{1}+(1-\delta) Q_{1}$.

2. At date $2,1-\delta$ units of this good will bring $(1-\delta) r_{2}$ units of aggregate good (as return) and $(1-\delta)^{2}$ units of the same asset (because of depreciation). Formally, $(1-\delta) Q_{1}=(1-\delta) \rho_{2} Q_{2}+(1-\delta)^{2} Q_{2}$.

Iterating the argument, we get the intertemporal no-arbitrage condition:

$$
\begin{aligned}
1 & =\left(\rho_{1}+1-\delta\right) Q_{1}=\rho_{1} Q_{1}+(1-\delta) Q_{1} \\
& =\rho_{1} Q_{1}+(1-\delta)\left(\rho_{2}+1-\delta\right) Q_{2}=\rho_{1} Q_{1}+(1-\delta) \rho_{2} Q_{2}+(1-\delta)^{2} Q_{2} \\
& =\cdots \\
& =\sum_{t=1}^{T}\left[(1-\delta)^{t-1} \rho_{t} Q_{t}\right]+(1-\delta)^{T} Q_{T}
\end{aligned}
$$

According to (24), what we pay at initial date to buy one unit of aggregate good equals what we expect to receive in the future. The first term in (24) is what the production process brings, while the second term is what any agent receives by reselling the aggregate good at date $T$.

The fundamental value of aggregate good at date 0 is defined as the sum of discounted values of its expected returns (net of depreciation):

$$
F V_{f}:=\sum_{t \geq 1}(1-\delta)^{t-1} \rho_{t} Q_{t}
$$

Definition 5 (bubble in aggregate good). There is a bubble in aggregate good if the price of aggregate good exceeds its fundamental value: $1>\sum_{t \geq 1}(1-\delta)^{t-1} \rho_{t} Q_{t}$, or, equivalently, $\lim _{t \rightarrow \infty}(1-\delta)^{T} Q_{T}>0$.

It is valuable to bridge our definition to the existing literature.

1. One-sector Ramsey model. Becker et al. (2015) define the bubble as a difference between 1 and the fundamental value of capital (discounted value of returns on capital: $\sum_{t>1}(1-\delta)^{t-1} r_{t} Q_{t}$. We define instead the bubble in aggregate good. These two concepts differ because the definitions of expected return $\rho_{t}$ and returns $r_{t}$ differ. Indeed, when the aggregate good is a pure consumption good $\left(F_{t}\right.$ no longer depends on $\left.K\right)$, we have $r_{t}=0$ for any $t$, which implies in turn a zero fundamental value of capital in Becker et al. (2015). However, as we will show in Section 5.2, the expected return $\rho_{t}$, defined by (20), may be strictly positive and the fundamental value of aggregate good be positive as well. Of course, these two concepts coalesce when $K_{t}>0$ for any $t$. This point will be readdressed in Section 5.2 
2. Full depreciation. When $\delta=1$, there is no bubble in aggregate good and the price of aggregate good at initial date equals its discounted value date date 1 , that is $1=\rho_{1} Q_{t}$.

3. Finite horizon. In the case of a T-horizon economy (Section 2.4), (24) holds. The price of aggregate good exceeds the discounted values of expected returns. This decomposition differs from that of capital good in (23). The last term $(1-\delta)^{T} Q_{T}$ is always positive because 1 unit of the aggregate good at initial date will depreciate to $(1-\delta)^{T}$ units of the same good at date $T$. This residual amount is not wasted, but consumed (see (10)).

Remark 4. We define the bubbles in aggregate and capital goods in the same way. However, we will see that these two kinds of bubbles behave differently because the structures of aggregate and capital goods are different.

We now introduce a new concept of bubble.

Definition 6 (investment bubble). There is an investment bubble if at least one of the asset markets experiences a bubble, that is

$$
q_{0}>F V_{k} \text { or } 1>F V_{f}
$$

There is a strong investment bubble if both the asset markets experience a bubble, that is

$$
q_{0}>F V_{k} \text { and } 1>F V_{f}
$$

\subsection{Literature on rational bubbles}

Theoretical literature supplies different concepts of rational bubbles depending on the definition of fundamental value and the kind of asset considered.

(1) Tirole (1982), Kocherlakota (1992, 2008), Santos and Woodford (1997), Huang and Werner (2000) and Le Van and Pham (2014) are general equilibrium models with long-lived assets. The structure of a long-lived asset is the following: an agent buys one unit of asset at date $t$ at a price $q_{t}$ and resells it at date $t+1$ at a price $q_{t+1}$ after receiving a dividend of $\xi_{t+1}$ units of consumption good. The sequence of dividends $\left(\xi_{t}\right)$ is exogenous. There exists a bubble if the market price of asset at date 0 (in terms of consumption good), say $q_{0}$, exceeds its fundamental value: $q_{0}>\sum_{t \geq 1} \Pi_{t} \xi_{t}$, where $\Pi_{t}$ is the discount factor of the economy from the initial date to date $t^{13}$

The capital good we consider is more general than the financial asset with exogenous dividends of standard literature. Indeed, the capital good is also a long-lived asset (it is resold and gives dividends at each date). That being said, their models differ from ours in three main respects: (1) the capital good depreciates while financial assets don't, $(2)$ the sequence of returns $\left(r_{h, t}\right)$ is endogenous while the sequence of financial dividends $\left(\xi_{t}\right)$ is exogenous, (3) the supply of capital good is also endogenous while the asset supply isn't.

\footnotetext{
${ }^{13} Q_{t}$ in our model plays the same role of $\Pi_{t}$ in their papers.
} 
Consider the case $\delta_{h}=G_{t}=0$. The supply of capital good at each date is now constant and equal to $H_{0}$. If $F_{t}(K, H)=F(K)+\xi_{t} H$ for any $t \geq 0$, we recover the long-lived asset in Tirole (1982), Kocherlakota (1992) and Huang and Werner (2000). In particular, when $\xi_{t}=0$ for any $t$, we recover the concept of pure bubble in Tirole (1985), Aoki et al. (2014), Hirano and Yanagawa (2013)

(2) Araujo et al. (2011) study equilibrium bubbles in durable goods and collateralized assets. Their asset-pricing equations (Corollary 1, page 263) rest on the existence of what they call deflators and non-pecuniary returns, that are not unique in general. Then, they define the bubbles associated to each sequence of deflators and non-pecuniary returns.

Focus on the asset-pricing equations $(18,19)$ and compare with Araujo et al. (2011). Our bubble corresponds to their bubble with deflators $\lambda_{i, t}$ where

$$
i \in \arg \max _{i \in\{1, \ldots, m\}}\left\{\beta_{i} u_{i}^{\prime}\left(c_{i, t+1}\right) / u_{i}^{\prime}\left(c_{i, t}\right)\right\},
$$

and non-pecuniary returns $\alpha_{i, t}=0$.

(3) Our concepts of bubble in aggregate and capital goods have also something to do with the bubble in firm's value defined by Miao and Wang $(2012,2015)$. Indeed, they also study bubbles in the firm's value with endogenous dividends. They consider a firm endowed with $K$ units of capital and decompose the value $V(K)$ (sum over time of discounted net profits) into two parts: $V(K)=Q K+B$, where $Q$ is the endogenous Tobin coefficient. They interpret $Q K$ as the firm's fundamental value and $B$ as a bubble in this value.

Their approach differs from ours in two respects. First, firms in Miao and Wang (2012, 2015) are dynamic credit-constrained firms and maximize a sum of discounted net profits, while firms in our model are static and maximize the profit period by period. Second, a bubble in Miao and Wang $(2012,2015)$ is the difference between the firm's market value and its fundamental value, while our bubble is the difference between the equilibrium asset price and its fundamental value.

\section{The nature of bubbles in capital good}

Let us characterize the existence of bubbles in capital good.

Proposition 1. The three following statements are equivalent.

(i) There exists a bubble in capital good.

(ii) $\lim _{t \rightarrow \infty}\left(1-\delta_{h}\right)^{t} Q_{t} q_{t}>0$.

(iii) $\sum_{t \geq 1} r_{h, t} / q_{t}<\infty$.

Proposition 1 recovers Montrucchio (2004) and Le Van and Pham (2014). Equivalences in Proposition 1 have important consequences. 
Corollary 1. 1. If bubbles in capital good exist, then $\sum_{t \geq 0} G_{t}^{\prime}\left(H_{t}^{k}\right)<\infty$.

2. Consider an equilibrium with $H_{t}^{k}>0$ for any $t$. A bubble in capital good exists if and only if $\sum_{t \geq 1} G_{t}^{\prime}\left(H_{t}^{k}\right)<\infty$.

Let us point out some other consequences of Proposition 1.

Corollary 2. Let $G$ be a strictly increasing and concave function with $G(0)=0$. Define a non-stationary production function $G_{t}=b_{t} G$ for every $t$ where $b_{t} \in[\underline{b}, \bar{b}]$ with $\underline{b}, \bar{b} \in(0, \infty)$. Suppose a positive capital good depreciation $\left(\delta_{h}>0\right)$. Then, equilibrium bubble in capital good are ruled out.

Focus now on the role of capital supply in the existence of bubbles in capital good.

Corollary 3. Assume that a positive constant d exists such that $G_{t}(H) \leq d G_{t}^{\prime}(H) H$ for any $t$ and $H \geq 0$.

If a bubble in capital good exists, then the aggregate stock of capital good $\left(H_{t}\right)$ is uniformly bounded from above.

\subsection{Sufficient (endogenous) conditions to rule out bubbles in capital good}

The main result rests on some intermediate lemmas. In primis, we show the impact of borrowing constraints following Le Van and Pham (2014).

Lemma 5. Consider an equilibrium and a particular agent $i$. If there is a date $t_{0}$ such that $k_{i, t+1}+q_{t} h_{i, t+1}>0$ for any $t \geq t_{0}$, then the limit $\lim _{t \rightarrow \infty} Q_{t}\left(k_{i, t+1}+q_{t} h_{i, t+1}\right)$ exists and equals 0.

Focus now on the role of the present value of profits.

Lemma 6. Consider an equilibrium and assume $\sum_{t \geq 0} Q_{t} \pi_{t}<\infty$. Then, $\lim _{t \rightarrow \infty} Q_{t} q_{t}\left(K_{t+1}+\right.$ $\left.q_{t} H_{t+1}\right)=0$.

Finally, consider the asymptotic discounted value of capital good.

Lemma 7. If $\lim _{t \rightarrow \infty} Q_{t} H_{t+1} q_{t}=0$, then $\lim _{t \rightarrow \infty}\left(1-\delta_{h}\right)^{t} Q_{t} q_{t}=0$.

Putting together these intermediate findings, we obtain immediately the main result.

Proposition 2. Bubbles in capital good are ruled out if one of the following condition is satisfied.

1. There exists $t_{0}$ such that $\beta_{i} u_{i}^{\prime}\left(c_{i, t}\right) / u_{i}^{\prime}\left(c_{i, t-1}\right)=\gamma_{t}$ for any $i$ and $t \geq t_{0}$.

2. There exists $t_{0}$ such that $\left(k_{i, t}, h_{i, t+1}\right) \neq 0$ for any $i$ and $t \geq t_{0}$. 


\section{3. $\sum_{t>0} Q_{t} \pi_{t}<\infty$.}

Inequality $H_{t+1} \geq\left(1-\delta_{h}\right) H_{t}$ is the center of Proposition 2. To grasp its implications, focus on a simplified case: $F_{t}(K, H)=F(K)+b_{t} H, G_{t}=0$ and $\delta_{h}=0$ (no depreciation). In this case, $H_{t+1}=H_{t}$ for any $t$ and the capital good behaves as the stock in Kocherlakota (1992) or the security in Santos and Woodford (1997). By the way, we generalize the well-known result in Kocherlakota (1992) and Santos and Woodford (1997): there is no financial bubble if the present value of aggregate endowments is finite.

In the case of zero profits, $\sum_{t \geq 0} Q_{t} \pi_{t}<\infty$ : thereby, we obtain an important corollary which applies to a prominent class of technologies.

Corollary 4. If $F_{t}$ and $G_{t}$ display constant returns to scale at any date $t$, then, bubbles in capital good are ruled out whatever equilibrium we consider.

\subsection{Examples of bubbles in capital good}

To illustrate our general results and understand their implications, we provide some examples of equilibrium bubbles in capital good.

We simplify the economy as follows. There are only 2 consumers: $A$ and $B$. Production functions are supposed to be linear

$$
F_{t}(K, H)=a_{t} K+b_{t} H+w, \quad G_{t}(H)=d_{t} H
$$

with $a_{t}, b_{t}, d_{t} \geq 0$ and $w>0$, to obtain constant profits over time: $\pi_{c, t}=w$ and $\pi_{k, t}=$ 0 for any $t$. Both the agents are supposed to be sufficiently impatient: $\beta\left(1-\delta+a_{t}\right) \leq 1$ for any $t \geq 0$.

As in Le Van and Pham (2015), we assume that profit shares fluctuate: $\left(\theta_{c, 2 t}^{A}, \theta_{c, 2 t+1}^{A}\right)=$ $(1,0)$ and $\left(\theta_{c, 2 t}^{B}, \theta_{c, 2 t+1}^{B}\right)=(0,1)$ for any $t$. Agent $B$ owns the initial endowments:

$$
k_{A, 0}=h_{A, 0}=0, k_{B, 0}=K_{0} \text { and } h_{B, 0}=H_{0}
$$

Collecting these pieces of information, we can construct an equilibrium.

Equilibrium prices are given by

$$
r_{t}=a_{t}, r_{h, t} \geq b_{t} \text { and } r_{h, t} \geq q_{t} d_{t}
$$

jointly with the no-arbitrage condition

$$
\left(1-\delta_{h}\right) q_{t+1}+r_{h, t+1}=q_{t}\left(1-\delta+a_{t+1}\right)
$$

These prices decentralize the equilibrium allocations:

(1) assets:

$$
\begin{aligned}
k_{A, 2 t} & =h_{A, 2 t}=0, k_{B, 2 t}=K_{2 t} \text { and } h_{B, 2 t}=H_{2 t} \\
k_{B, 2 t+1} & =h_{B, 2 t+1}=0, k_{A, 2 t+1}=K_{2 t+1} \text { and } h_{A, 2 t+1}=H_{2 t+1}
\end{aligned}
$$


(2) consumption good:

$$
\begin{aligned}
c_{A, 2 t} & =\frac{w}{1+\beta} \text { and } c_{B, 2 t}=\left(1-\delta+r_{2 t}\right) \frac{\beta w}{1+\beta} \\
c_{A, 2 t+1} & =\left(1-\delta+r_{2 t+1}\right) \frac{\beta w}{1+\beta} \text { and } c_{B, 2 t+1}=\frac{w}{1+\beta}
\end{aligned}
$$

(3) dynamics of aggregate and capital goods:

$$
\begin{aligned}
K_{t+1} & =\frac{\beta w}{1+\beta}-q_{t} H_{t+1} \\
H_{t+1} & =\left(1-\delta_{h}\right) H_{t}+d_{t} H_{t}^{k} \\
H_{t} & =H_{t}^{c}+H_{t}^{k}
\end{aligned}
$$

with $K_{t}, H_{t}^{c}, H_{t}^{k} \geq 0$.

These prices and allocations constitute an equilibrium (see Appendix).

\subsubsection{Continuum of equilibrium prices with bubble in capital good}

Focus on the case where $d_{t}=0$ and $b_{t}>0$ : the capital good is no longer produced but it can be used to produce the aggregate good. ${ }^{14}$ In this case, $r_{h, t}=b_{t}>0$, $H_{t}^{k}=0, H_{t}^{c}=H_{t}=H_{0}\left(1-\delta_{h}\right)^{t}$ and $Q_{t}=\left[\left(1-\delta+a_{1}\right) \cdots\left(1-\delta+a_{t}\right)\right]^{-1}$ for any $t$. Let $D:=\sum_{t>1}\left(1-\delta_{h}\right)^{t-1} b_{t} Q_{t}$ denote the discounted value of depreciated returns on capital good. Of course, $D=0$ if $b_{t}=0$ for any $t$. We assume also $H_{1} D<\beta w /(1+\beta)$. It is immediate to see that the fundamental value of capital good is $F V_{k}=D$.

We consider $q_{0}=B+D$ with $B \geq 0$ and we determine the sequence of asset prices $\left(q_{T}\right)_{T \geq 1}$ from

$$
q_{0}=\sum_{t=1}^{T}\left[\left(1-\delta_{h}\right)^{t-1} b_{t} Q_{t}\right]+\left(1-\delta_{h}\right)^{T} q_{T} Q_{T}
$$

To ensure the positivity of aggregate good $\left(K_{t}>0\right)$, we assume

$$
H_{1}\left(B+D-\sum_{t=1}^{T}\left(1-\delta_{h}\right)^{t-1} b_{t} Q_{t}\right)\left(1-\delta+a_{1}\right) \cdots\left(1-\delta+a_{T}\right)<\frac{\beta w}{1+\beta}
$$

for any $T \geq 1$. This condition depends on $\left(a_{t}\right),\left(b_{t}\right), w, B, \beta, \delta, \delta_{h}$ and $H_{1}$.

Inequality (30) entails that any

$$
q_{0} \in\left[D, \frac{\beta w}{(1+\beta)(1-\delta) H_{0}}\right)
$$

is an equilibrium price of capital good at date $0 .{ }^{15}$ Moreover, if $q_{0}>D$, then this equilibrium price is bubbly.

\footnotetext{
${ }^{14}$ The capital good is an input with depreciation rate $\delta_{h} \geq 0$.

${ }^{15}$ Notice that

$$
q_{0}<\frac{\beta w}{(1+\beta)(1-\delta) H_{0}} \Rightarrow K_{1}=\frac{\beta w}{(1+\beta)}-q_{0} H_{1}>0
$$
}


Remark 5. If $b_{t}=0$ for any $t$, the capital good becomes a pure bubble (without intrinsic value) like in Tirole (1985).

\subsubsection{Unique equilibrium price with bubble in capital good}

Consider now the case where $b_{t}>0$ and $d_{t}>0$. We assume no depreciation of aggregate good $(\delta=0)$ and a partial depretiation of capital good $\left(\delta_{h} \in(0,1)\right)$. Moreover,

$$
b_{t}=b>0, a_{t}=d_{t-1} \text { and } d_{t+1}=\left(1-\delta_{h}\right) d_{t}
$$

and

$$
\frac{b\left(1+d_{0}\right) \cdots\left(1+d_{t-1}\right) H_{1}}{\left(1-\delta_{h}\right) d_{0}} \leq \frac{\beta w}{1+\beta}
$$

for any $t$. Condition (32) can be satisfied since $\Pi_{t \geq 0}\left(1+d_{t}\right)<\infty$. $^{16}$

Equilibrium prices are given by $r_{t}=a_{t}$ and $r_{h, t}=b=q_{t} d_{t}$. Thank to this and (31), condition (26) is satisfied.

We now verify that $(27,28,29)$ also hold. We have just to prove that $q_{t} H_{t+1}<$ $\beta w /(1+\beta)$. We have

$$
\begin{aligned}
H_{t+1} & \leq\left(1-\delta_{h}+d_{t}\right) H_{t}=\left(1-\delta_{h}\right)\left(1+d_{t-1}\right) H_{t} \\
& \leq \cdots \leq\left(1-\delta_{h}\right)^{t}\left(1+d_{t-1}\right) \cdots\left(1+d_{0}\right) H_{1}
\end{aligned}
$$

and, therefore,

$$
q_{t} H_{t+1}=\frac{b H_{t+1}}{d_{t}} \leq \frac{b\left(1-\delta_{h}\right)^{t}\left(1+d_{t-1}\right) \cdots\left(1+d_{0}\right) H_{1}}{\left(1-\delta_{h}\right)^{t+1} d_{0}}=\frac{b\left(1+d_{t-1}\right) \cdots\left(1+d_{0}\right) H_{1}}{\left(1-\delta_{h}\right) d_{0}}
$$

By combining this with (32), we obtain that $q_{t} H_{t+1}<\beta w /(1+\beta)$.

In this example, a bubble in capital good exists if and only if $\sum_{t \geq 1} d_{t}<\infty$. This condition holds because $d_{t+1}=\left(1-\delta_{h}\right) d_{t}$ and $\delta_{h}>0$.

\section{The nature of bubbles in aggregate good}

To understand the nature of bubbles in aggregate good, we start with their carachterization. As Proposition 1, the following bridge the existence of bubbles with the structure of returns.

Proposition 3. The following statements are equivalent.

(i) There exists a bubble in aggregate good.

(ii) $\lim _{t \rightarrow \infty}(1-\delta)^{t} Q_{t}>0$.

(iii) Interest rates are low, that is $\sum_{t \geq 1} \rho_{t}<+\infty$.

\footnotetext{
${ }^{16}$ Condition $\Pi_{t \geq 0}\left(1+d_{t}\right)<\infty$ is equivalent to $\sum_{t \geq 0} d_{t}<\infty$. In our example, we have $\sum_{t \geq 0} d_{t}<$ $\infty$ because $d_{t+1}=\left(1-\delta_{h}\right) d_{t}$ and $\delta_{h}>0$.
} 
The novelty of Proposition 3 rests on a necessary and sufficient condition which characterize the existence of bubbles in aggregate good: $\sum_{t \geq 1} \rho_{t}<\infty$. We call this inequality condition of low interest rates. The intuition behind is the following: the lower the level of returns, the lower the fundamental value of aggregate good. Thereby, when returns becomes low enough, bubbles in aggregate good emerge. Indeed, according to (24), the equilibrium price of capital at the initial date equals the sum of its fundamental value and the bubble component:

$$
1=\sum_{t \geq 1}(1-\delta)^{t-1} \rho_{t} Q_{t}+\lim _{t \rightarrow \infty}(1-\delta)^{t} Q_{t}
$$

This component writes more explicitly:

$$
B_{f}=\lim _{t \rightarrow \infty}(1-\delta)^{t} Q_{t}=\lim _{t \rightarrow \infty} \frac{(1-\delta)^{t}}{\left(1-\delta+\rho_{1}\right) \ldots\left(1-\delta+\rho_{t}\right)}
$$

It is easy to see that $B_{f}$ is decreasing in each $\rho_{t}$. Therefore, the fundamental value $F V_{f}=1-B_{f}$ is increasing in each return $\rho_{t}$. Thus, when returns are low enough, the fundamental value falls below 1 and a bubble appears.

Remark 6. We see that one unit of aggregate good at initial date will depreciate to $(1-\delta)^{t}$ units of the same asset at date $t$. The discounted value of these $(1-\delta)^{t}$ units is $Q_{t}(1-\delta)^{t}$. Therefore, bubbles in aggregate good can be interpreted as the discounted market value (at the infinity) of one unit of capital at the initial date after depreciation.

As Corollary 2, the following gives a sufficient condition to rule out bubbles in aggregate good.

Corollary 5. Let $F, G$ be increasing and concave production functions with $F(0,0)=$ $G(0)=0$. Assume that (1) $F_{t}=a_{t} F$ for every $t$ where $a_{t} \in[\underline{a}, \bar{a}]$ with $\underline{a}, \bar{a} \in(0, \infty)$, and (2) $G_{t}=b_{t} G$ for every $t$ where $b_{t} \in[\underline{b}, \bar{b}]$ with $\underline{b}, \bar{b} \in(0, \infty)$. Assume also that $0<\bar{b} G^{\prime}(\infty)<\delta_{h}$. Then, there is no equilibrium bubble in aggregate good.

Becker et al. (2015) consider a one-sector model with endogenous labor supply. They introduce a specific condition on a stationary production function under which the capital stocks turns out to be uniformly bounded. ${ }^{17}$ They prove that bubbles in aggregate good never arise. Conversely, we don't require any specific condition on the production functions (our conclusions hold also in the case of AK technology). Nevertheless, we observe that a stationary technology rules out the bubble in aggregate good even in our model according to Corollary 5. In this respect, the no-bubble result in Becker et al. (2015) can be viewed as a particular case of ours.

In what follows, we present some examples where bubbles in aggregate good arise.

${ }^{17}$ More precisely, they consider a production function $F(K, L)$ with

$$
\frac{\partial F}{\partial K}(\infty, m)=\frac{\partial F}{\partial L}(1, \infty)=0
$$




\subsection{On bubbles in aggregate good in one-sector models}

We show by means of example that bubbles in aggregate good may arise even when (1) the present value of output is finite, (2) all consumers are identical, (3) borrowing constraints of consumers are never binding.

Consider a simple AK model without capital good where all consumers have the same preferences: $u_{i}(c)=\ln (c)$ and $\beta_{i}=\beta$ for any $i$. Technology is non-stationary: $F_{t}(K)=a_{t} K$ for any $t$. We normalize the price of aggregate good: $p_{t}=1$ and $r_{t}=a_{t}$ for any $t$.

According to Lemma 10 (see Appendix 9.3), the individual accumulation of aggregate good is given by $k_{i, t+1}=\beta\left(1-\delta+a_{t}\right) k_{i, t}$. The allocation of agent $i$ becomes

$$
\begin{aligned}
k_{i, t} & =\beta^{t}\left(1-\delta+a_{0}\right) \cdots\left(1-\delta+a_{t-1}\right) k_{i, 0} \\
c_{i, t+1} & =\beta\left(1-\delta+a_{t+1}\right) c_{i, t}
\end{aligned}
$$

with $c_{i, 0}=(1-\beta)\left(1-\delta+a_{0}\right) k_{i, 0}$. The aggregate capital stock is given by

$$
K_{t}=\beta^{t}\left(1-\delta+a_{0}\right) \cdots\left(1-\delta+a_{t-1}\right) \sum_{i} k_{i, 0} .
$$

The above sequence of prices and allocations $\left(p_{t}, r_{t},\left(c_{i}, k_{i}\right), K\right)$ is an equilibrium. Finally, we compute the discount factor and the aggregate output $Y_{t}:=F_{t}\left(K_{t}\right)+$ $(1-\delta) K_{t}$ :

$$
\begin{aligned}
Q_{t} & =\frac{1}{\left(1-\delta+a_{1}\right) \ldots\left(1-\delta+a_{t}\right)} \\
Y_{t} & =\left(1-\delta+a_{t}\right) K_{t}=\left(1-\delta+a_{t}\right) \sum_{i=1}^{m} k_{i, t}=\beta^{t}\left(1-\delta+a_{0}\right) \ldots\left(1-\delta+a_{t}\right) K_{0}
\end{aligned}
$$

\subsubsection{Bubble in aggregate good and the present value of output}

A well-known result on bubble in financial asset is that, if the present value of aggregate endowments is finite, there is no bubble (see Kocherlakota (1992), Santos and Woodford (1997), Huang and Werner (2000)). In one-sector models, the present value of output is defined as

$$
F V=\sum_{t \geq 1} Q_{t} Y_{t}
$$

We see that this value of output is finite for every sequence $\left(a_{t}\right)_{t}$. Indeed,

$$
F V=\sum_{t \geq 1} Q_{t} Y_{t}=\left(1-\delta+a_{0}\right) K_{0} \sum_{t \geq 1} \beta^{t}<\infty
$$

According to Proposition 3, when $\sum_{t \geq 1} a_{t}=\infty$, there is no room for bubbles in aggregate good. When $\sum_{t \geq 1} a_{t}<\infty$, bubbles exist in aggregate good. Anyway, in both the cases, the present value of output is finite. Thus, in the one-sector model, there is no causal relationship between the existence of bubbles in aggregate good and a finite present value of output. 


\subsubsection{Bubbles in aggregate good, borrowing constraints and heteroge- neous agents}

In the above examples, $k_{i, t}>0$ for any $i$ and $t$. Hence, bubbles in aggregate good may arise when the borrowing constraints are not binding. This is different from what we observe in standard models with pure financial assets such as Kocherlakota (1992, 2008), Santos and Woodford (1997), Huang and Werner (2000) and Le Van and Pham (2014).

Surprisingly, in the above example, bubbles in aggregate good may occur with identical consumers.

\subsection{Bubble in pure consumption good}

Focus now on a case without capital good, where the aggregate good is consumed but not used to produce. This good remains storable and allows agents to transfer wealth over time.

We consider a unique (representative) consumer with utility function $u(c)=\ln c$. The production function is simply given by $F_{t}(K)=w_{t}$ where $w_{t} \geq 0$ is exogenous. ${ }^{18}$ Thus, the sequence of profits is driven by the exogneous process: $\pi_{t}=w_{t}$. Even if the returns on capital are zero $\left(r_{t}=0\right)$, the expected returns may be strictly positive (see below).

The representative consumer solves the program

$$
\begin{aligned}
P: & \max _{\left(c_{t}, k_{t+1}\right)_{t=0}^{\infty}} \sum_{t=0}^{\infty} \beta^{t} \ln c_{t} \\
c_{t}+k_{t+1} & \leq(1-\delta) k_{t}+w_{t} \\
k_{t+1} & \geq 0
\end{aligned}
$$

whose solution depends on the shape of the process $\left(w_{t}\right)$.

Lemma 8. 1. If $w_{t+1}=\beta(1-\delta) w_{t}$ for any $t \geq 0$, then the unique solution to problem $P$ is given by $k_{t+1}=\beta(1-\delta) k_{t}$ for any $t \geq 0$.

2. If $w_{t+1}>\beta(1-\delta) w_{t}$ for any $t$, then the unique solution to program $P$ is given by $k_{t}=0$ for any $t \geq 1$.

We can use the same argument in Lemma 10 (see Appendix 9.3) to prove Lemma 8. The proof is left to the reader.

\subsubsection{Pure bubbles with zero expected returns}

We consider the case where $w_{t+1}=\beta(1-\delta) w_{t}$ for any $t$. In this case, according to Lemma 8 , we have $1=(1-\delta) \beta u^{\prime}\left(c_{t+1}\right) / u^{\prime}\left(c_{t}\right)$. Therefore, the expected returns of aggregate good, defined by $(20)$, are zero $\left(\rho_{t}=0\right.$ for any $\left.t\right)$ and the fundamental value of aggregate good is null. We obtain $1=Q_{t}(1-\delta)^{t}$ for any $t$ and the bubble coincides with the (positive) price of aggregate good.

\footnotetext{
${ }^{18}$ This function is a reduced form of a production function $F_{t}(K, L)=w_{t} L$ with exogenous labor supply. For simplicity, labor forces are normalized to 1.
} 


\subsubsection{No-trade equilibrium with bubble and positive expected returns}

Consider now the case where $w_{t+1}>\beta(1-\delta) w_{t}$. According to Lemma 8 , we have $k_{t}=0$ for any $t \geq 1$. Thus, $c_{t}=w_{t}$ for any $t \geq 0$ and we can compute the expected returns $\left(\rho_{t}\right)$ as follows

$$
\rho_{t+1}=\frac{1}{\frac{\beta u^{\prime}\left(c_{t+1}\right)}{u^{\prime}\left(c_{t}\right)}}-(1-\delta) .
$$

Therefore, we get that $\rho_{t+1}=w_{t+1} /\left(\beta w_{t}\right)-(1-\delta)$ which is positive. ${ }^{19}$ Bubbles in aggregate good exist if and only if $\sum_{t \geq 1} \rho_{t}<\infty$. Of course, the existence of bubbles in aggregate good depends on the form of the exogenous process $\left(w_{t}\right)$ which affects in turn the sequence of expected returns $\left(\rho_{t}\right)$.

Remark 7. In this case, the discounted value of returns on capital is zero: $\sum_{t \geq 1}(1-$ $\delta)^{t-1} r_{t} Q_{t}=0$, but the fundamental value of aggregate good is strictly positive: $\sum_{t \geq 1}(1-$ $\delta)^{t-1} \rho_{t} Q_{t}>0$.

\section{On the difference between bubbles in aggregate and capital goods}

So far, we have shown the nature of both kinds of bubbles. Now, we compare them highlighting similarities and differences.

First, both bubbles may arise at equilibrium (strong investment bubble). In Example 4.2.1, we choose a sequence of returns $\left(a_{t}\right)$ such that $\sum_{t>1} a_{t}<\infty$ and we get both bubbles in capital and aggregate good. ${ }^{20}$ Of course, there are some cases where one of two bubbles exists but the other one may not (investment bubble), or neither of them exists.

Second, although the formal definition of both bubbles is the same, they are very different. Indeed, the bubble in capital good cannot emerge if the discount factors of agents are identical or if borrowing constraints of agents are not binding or if the present value of profits is finite. By contrast, the bubble in aggregate good may appear even if these three conditions are violated. These interesting differences come from the structural difference between aggregate and capital goods: indeed, the aggregate good is not only consumed but also used to produce while the capital good is only processed in production. To see the point, we consider an economy where consumers are identical. The bubble in capital good is given by $B_{f}:=\lim _{t \rightarrow \infty} Q_{t} q_{t}(1-$ $\left.\delta_{h}\right)^{t}$, the discounted value of $\left(1-\delta_{h}\right)^{t}$ units of capital good at the infinity. Since the consumer is representative and rational, the discounted value of capital good at

\footnotetext{
${ }^{19}$ Setting $w_{t+1} / w_{t}=1+r_{w, t+1}$ where $r_{w, t+1}$ is the growth rate of labor productivity, and $1 / \beta=$ $1+i$, we obtain $\rho_{t}=\left[\left(1+r_{w, t+1}\right)(1+i)-1\right]+\delta$. This return can be interpreted as the real interest rate of the economy.

${ }^{20}$ In Example 4.2.2, we have a converging series $\sum_{t \geq 1} a_{t}<\infty$. Aggregate and capital goods bubbles also arise.
} 
infinity equals zero: $\lim _{t \rightarrow \infty} Q_{t} q_{t} H_{t+1}=0 .{ }^{21}$ Moreover, since the capital good cannot be consumed, the amount of capital good rent in the rental market at each date exceeds the depreciated capital supply from the previous date: $H_{t} \geq\left(1-\delta_{h}\right) H_{t-1}$ and $H_{t} \geq H_{0}\left(1-\delta_{h}\right)^{t}$. By consequence, the limit $\lim _{t \rightarrow \infty} Q_{t} q_{t}\left(1-\delta_{h}\right)^{t}$ is zero. Thus, there is no bubble in capital good with a unique consumer. However, this argument does not work in the case of aggregate good. For two reasons.

First, give a quick look to the aggregate good market clearing condition:

$$
C_{t}+K_{t+1}=(1-\delta) K_{t}+F_{t}\left(K_{t}, H_{t}^{c}\right)
$$

Since the aggregate good can be consumed, the difference between the amount of aggregate good rent in the rental market and the depreciated aggregate good $K_{t+1}-$ $(1-\delta) K_{t}$ can take any value either positive or negative. Thereby, $\lim _{t \rightarrow \infty} Q_{t} K_{t+1}=0$ no longer implies $\lim _{t \rightarrow \infty} Q_{t}(1-\delta)^{t}=0$.

Second, the bubble in capital good equals the discounted value of $\left(1-\delta_{h}\right)^{t}$ units of capital good at infinity: this amount can only traded in the rental market (of capital good). By contrast, the bubble in aggregate good is equal to the discounted value of $\left(1-\delta_{h}\right)^{t}$ units of aggregate good at infinity: this amount may be not only traded in the rental market (of aggregate good) but also consumed. That is why there is more room for bubbles in aggregate good.

These arguments suggest that different assets may generate very different bubbles.

\section{$7 \quad$ Efficiency of equilibrium production plans}

We apply to our model the concept of efficiency introduced by Malinvaud (1953). For simplicity, we normalize the prices of aggregate good: $p_{t}=1$ for any $t$.

Definition 7. Let $F_{t}, G_{t}$ be production functions and $\delta$ be the capital depreciation rate. that

A feasible path of production plan is a positive sequence $\left(K_{t}, H_{t}, H_{t}^{c}, K_{t}^{k}\right)$ such

$$
\begin{aligned}
C_{t} & :=(1-\delta) K_{t}+F_{t}\left(K_{t}, H_{t}^{c}\right)-K_{t+1} \geq 0 \\
H_{t+1} & =\left(1-\delta_{h}\right) H_{t}+G_{t}\left(H_{t}^{k}\right) \\
H_{t}^{c}+H_{t}^{k} & =H_{t}
\end{aligned}
$$

for every $t$, where $\left(K_{0}, H_{0}, H_{0}^{c}, H_{0}^{k}\right)$ is given with $H_{0}=H_{0}^{c}+H_{0}^{k}$.

For each feasible production plan, a feasible path is efficient if there is no other feasible path $\left(K_{t}^{\prime}, H_{t}^{\prime}, H_{t}^{c^{\prime}}, H_{t}^{k^{\prime}}\right)$ such that

$$
C_{t}^{\prime} \geq C_{t}
$$

for every $t$ with strict inequality for some $t$.

\footnotetext{
${ }^{21}$ Recall that, when agents are identical, their transversality conditions write $\lim _{t \rightarrow \infty} \beta^{t} u^{\prime}\left(c_{t}\right) q_{t} h_{t}=0$. This implies $\lim _{t \rightarrow \infty} Q_{t} q_{t} H_{t}=0$.
} 
Definition 8. An intertemporal equilibrium is efficient if its production plan $\left(K_{t}, H_{t}, H_{t}^{c}, H_{t}^{k}\right)$ is efficient.

These definitions imply the following sufficient condition.

Lemma 9. An equilibrium is efficient if $\lim _{t \rightarrow \infty} Q_{t}\left(K_{t+1}+q_{t} H_{t+1}\right)=0$.

The next proposition and corollary bring the main results on efficiency.

Proposition 4. An equilibrium is efficient if one of the following conditions is satisfied.

1. There exists $t_{0}$ such that $\gamma_{t}=\beta_{i} u_{i}^{\prime}\left(c_{i, t}\right) / u_{i}^{\prime}\left(c_{i, t-1}\right)$ for any $i$ and $t \geq t_{0}$.

2. There exists $t_{0}$ such that $k_{i, t}>0$ for any $i$ and $t \geq t_{0}$.

3. $\sum_{t=0}^{\infty} Q_{t} \pi_{t}<\infty$.

We should mention here that Becker et al. (2014) give an example of inefficient equilibrium (an equilibrium three-period cycle) where borrowing constraints are binding at infinitely many dates.

According to Proposition 4, when profits equal zero, every equilibrium is efficient. The particular (but prominent) case of zero profit CRS technologies is considered in the following corollary.

Corollary 6. Assume that $F_{t}$ and $G_{t}$ are constant returns to scale for any $t$. Then, every equilibrium path is efficient.

This result differs from those obtained by Cass (1972), Becker and Mitra (2012), Mitra and Ray (2012) in two respects: (1) we allow for linear technologies (while they consider strictly concave production functions), (2) we don't need bounded capital stocks (as it is the case in their papers).

\subsection{Efficiency and bubbles in one-sector models}

It is immediate to see that all the results on equilibrium efficiency in our generalized two-sector model also apply to the one-sector models by Becker et al. (2015).

Interestingly, there is room for both efficiency and bubbles in aggregate good in the one-sector model. Indeed, Section 5.1 and Corollary 6 show that there exists an efficient bubbly equilibrium. We are not surprised: the existence of bubbles rests on the low returns while equilibrium efficiency on capital distribution. 


\subsection{Final remarks on transversality conditions}

\subsubsection{Capital good}

We have encountered three different conditions, but closely related to the transversality condition for capital good.

$$
\begin{array}{r}
\lim _{t \rightarrow \infty} \beta_{i}^{t} u_{i}^{\prime}\left(c_{i, t}\right) q_{t} h_{i, t+1}=0 \\
\lim _{t \rightarrow \infty}\left(1-\delta_{h}\right)^{t} Q_{t} q_{t}=0 \\
\lim _{t \rightarrow \infty} Q_{t} q_{t} H_{t+1}=0
\end{array}
$$

(34) is the standard transversality condition satisfied by optimal allocations. According Lemma 2, condition (34) always holds at equilibrium.

(35) is a condition of no bubble in capital good. It may fail because bubble in capital good exists at equilibrium.

$\lim _{t \rightarrow \infty} Q_{t} q_{t} H_{t+1}$ is the discounted value of the capital good at infinity. Therefore, we call (36) vanishing capital good condition. According to Lemma 5, condition (36) is satisfied if $Q_{t}=\beta_{i}^{t} u_{i}^{\prime}\left(c_{i, t}\right) / u_{i}^{\prime}\left(c_{i, 0}\right)$ for any $i$. According to Lemma 7, condition (36) implies condition (35).

\subsubsection{Aggregate good}

We have also encountered three other distinct conditions, but closely related to the transversality condition for aggregate good.

$$
\begin{array}{r}
\lim _{t \rightarrow \infty} \beta_{i}^{t} u_{i}^{\prime}\left(c_{i, t}\right) k_{i, t+1}=0 \\
\lim _{t \rightarrow \infty}(1-\delta)^{t} Q_{t}=0 \\
\lim _{t \rightarrow \infty} Q_{t} K_{t+1}=0
\end{array}
$$

According to Lemma 2, standard transversality condition (37) always holds in equilibrium. Conditions (38) may fail because there is room for equilibrium bubbles in aggregate good. (39) may also fail: Becker et al. (2014) gives an example violating condition (39). ${ }^{22}$

We observe that condition (39) does not imply condition (38) since $K_{t+1}-(1-$ $\delta) K_{t}$ may be negative. Let us reconsider the example of one-sector economy with a representative consumer (Section 5.1). In this example, condition (39) becomes a transversality condition and, therefore, holds at equilibrium. Moreover, the equilibrium is efficient. However, the no-bubble condition (38) holds if and only if $\sum_{t \geq 1} a_{t}=\infty$. We conclude that transversality and no-bubble conditions are different.

\footnotetext{
${ }^{22}$ They construct an inefficient equilibrium in a one-sector model. This entails the failure of (39).
} 


\section{Conclusion}

We have introduced the concept of bubbles in aggregate and capital goods. Both these assets may depreciate and are endogenously supplied. The aggregate good is processed in production and consumed, while the capital good is a pure input. The meaning of capital good is intendenly large. It can be viewed as a machine, a Lucas tree, land, ....). Because of their different structure, these two goods generate very different kinds of bubbles.

We have shown that an equilibrium is efficient if (1) the consumers' borrowing constraints are not binding from some date on or (2) the present value of outputs is finite. Interestingly, it is possible to have both equilibrium bubbles and efficiency in a one-sector model.

\section{Appendices: formal proofs}

\subsection{Proofs for Section 3}

Proof of Lemma 4. First, we write all FOCs for the economy $\mathcal{E}$. Denote by $\lambda_{i, t}$ the multiplier with respect to the budget constraint of agent $i$ and by $\nu_{i, t+1}, \mu_{i, t+1}$ the multipliers with respect to borrowing constraints $k_{i, t+1} \geq 0, h_{i, t+1} \geq 0$, of agent $i$.

$$
\begin{aligned}
\beta_{i}^{t} u_{i}^{\prime}\left(c_{i, t}\right) & =\lambda_{i, t} \\
\lambda_{i, t} & \left.=\lambda_{i, t+1}\left(r_{t+1}+1-\delta\right)\right)+\nu_{i, t+1}, \quad \nu_{i, t+1} k_{i, t+1}=0 \\
\lambda_{i, t} q_{t} & =\lambda_{i, t+1}\left(r_{h, t+1}+q_{t+1}\left(1-\delta_{h}\right)\right)+\mu_{i, t+1}, \quad \mu_{i, t+1} h_{i, t+1}=0 .
\end{aligned}
$$

Therefore, we have

$$
\begin{aligned}
1 & \geq \frac{\beta_{i} u_{i}^{\prime}\left(c_{i, t+1}\right)}{u_{i}^{\prime}\left(c_{i, t}\right)}\left(r_{t+1}+1-\delta\right) \\
q_{t} & \geq \frac{\beta_{i} u_{i}^{\prime}\left(c_{i, t+1}\right)}{u_{i}^{\prime}\left(c_{i, t}\right)}\left(r_{h, t+1}+\left(1-\delta_{h}\right) q_{t+1}\right)
\end{aligned}
$$

for every $i$.

By combining (9) and the fact that $1-\delta_{h}>0$, we obtain that $H_{t}>0$ for any $t$. Therefore, there exists $i$ such that $h_{i, t+1}>0$. For such an agent, we have $\mu_{i, t+1}=0$. Consequently, we get (18).

(43) implies that $1 \geq \gamma_{t+1}\left(r_{t+1}+1-\delta\right)$. If $K_{t+1}>0$, there exists $i_{0}$ such that $k_{i_{0}, t+1}>0$, and then $\nu_{i_{0}, t+1}=0$. For such $i_{0}$, we have $1=\frac{\beta_{i_{0}} u_{i_{0}}^{\prime}\left(c_{i_{0}, t+1}\right)}{u_{i, 0}^{\prime}\left(c_{i_{0}, t}\right)}\left(r_{t+1}+1-\delta\right)$. Therefore, $\frac{\beta_{i_{0}} u_{i_{0}}^{\prime}\left(c_{i_{0}, t+1}\right)}{u_{i, 0}^{\prime}\left(c_{i_{0}, t}\right)}=\gamma_{t+1}$.

\subsection{Proofs for Section 4}

Proof of Proposition 1. According to (22), we see that (i) is equivalent to (ii). 
We now prove that (ii) is equivalent to (iii). According to (18), we obtain that

$$
q_{t} Q_{t}=\left(r_{h, t+1}+\left(1-\delta_{h}\right) q_{t+1}\right) Q_{t+1}=\left(\frac{r_{h, t+1}}{\left(1-\delta_{h}\right) q_{t+1}}+1\right)(1-\delta) q_{t+1} Q_{t+1} .
$$

Hence, we have, for any $T \geq 1$,

$$
q_{0}=\left(1-\delta_{h}\right)^{T} q_{T} Q_{T} \prod_{t=1}^{T}\left(\frac{r_{h, t}}{\left(1-\delta_{h}\right) q_{t}}+1\right) .
$$

Consequently, we see that $\lim _{t \rightarrow \infty}\left(1-\delta_{h}\right)^{t} q_{t} Q_{t}>0$ if and only if $\prod_{t \geq 1}\left(1+\frac{r_{h, t}}{\left(1-\delta_{h}\right) q_{t}}\right)<\infty$. This condition is equivalent to $\sum_{t \geq 1} \frac{r_{h, t}}{q_{t}}<\infty$.

Proof of Corollary 2. According to the capital market clearing condition, we have

$$
H_{t+1}=\left(1-\delta_{h}\right) H_{t}+G_{t}\left(H_{t}^{k}\right) \leq\left(1-\delta_{h}\right) H_{t}+b_{t} G\left(H_{t}\right)
$$

for any $t$.

Case 1: $\bar{b} G^{\prime}(\infty) \geq \delta_{h}$. Therefore, we have $G_{t}^{\prime}\left(H_{t}^{k}\right)=b_{t} G^{\prime}\left(H_{t}^{k}\right) \geq \bar{b} G^{\prime}(\infty) \underline{b} / \bar{b} \geq$ $\delta_{h} \underline{b} / \bar{b}$ for every $t$. As a result, $\sum_{t \geq 1} G_{t}^{\prime}\left(H_{t}^{k}\right)=\infty$. According to Corollary 1 , capital good bubbles are ruled out.

Case 2: $\bar{b} G^{\prime}(\infty)<\delta_{h}$. According to Lemma 1, the aggregate capital stocks $\left(H_{t}\right)$ are uniformly bounded from above, i.e., there exists $\bar{H} \in(0, \infty)$ such that $H_{t} \leq H$ for any $t$. Consequently, $G_{t}^{\prime}\left(H_{t}^{k}\right) \geq b_{t} G^{\prime}\left(H_{t}\right)>\underline{b} G^{\prime}(\bar{H})>0$ for every $t$. This implies that $\sum_{t \geq 1} G_{t}^{\prime}\left(H_{t}^{k}\right)=\infty$. According to Corollary 1 , there is no bubble.

Proof of Corollary 3. We have

$$
H_{t+1}=\left(1-\delta_{h}\right) H_{t}+G_{t}\left(H_{t}^{k}\right) \leq H_{t}+d G_{t}^{\prime}\left(H_{t}^{k}\right) H_{t}^{k} \leq H_{t}\left(1+d G_{t}^{\prime}\left(H_{t}^{k}\right)\right) .
$$

Since capital good bubbles exist, we have $\sum_{t \geq 0} G_{t}^{\prime}\left(H_{t}^{k}\right)<\infty$. This implies that $\prod_{t=0}^{\infty}(1+$ $\left.d G_{t}^{\prime}\left(H_{t}^{k}\right)\right)<\infty$. Therefore, the capital stock $\left(H_{t}\right)$ is uniformly bounded from above.

Proof of Lemma 5. Assume that there exists $t_{0}$ such that $k_{i, t+1}+q_{t} h_{i, t+1}>0$ for any $t \geq t_{0}$. Then, according to Remark 3 , we have, for every $t \geq t_{0}$

$$
\frac{Q_{t}}{Q_{t_{0}}}=\beta_{i}^{t-t_{0}} \frac{u_{i}^{\prime}\left(c_{i, t}\right)}{u_{i}^{\prime}\left(c_{i, t_{0}}\right)}
$$

According to Lemma 2, we have

$$
\lim _{t \rightarrow \infty} \beta_{i}^{t} u_{i}^{\prime}\left(c_{i, t}\right) k_{i, t+1}=\lim _{t \rightarrow \infty} \beta_{i}^{t} u_{i}^{\prime}\left(c_{i, t}\right) h_{i, t+1} q_{t}=0 .
$$

Hence, $\lim _{t \rightarrow \infty} Q_{t}\left(k_{i, t+1}+h_{i, t+1} q_{t}\right)=0$. 
Proof of Lemma 6. We have

$$
Q_{t} c_{i, t}+Q_{t} k_{i, t+1}+Q_{t} q_{t} h_{i, t+1}=Q_{t}\left(r_{t}+1-\delta\right) k_{i, t}+Q_{t}\left(r_{h, t}+\left(1-\delta_{h}\right) q_{t}\right) h_{i, t}+Q_{t} \pi_{i, t} .
$$

It is easy to see that $Q_{t+1}\left(r_{h, t+1}+\left(1-\delta_{h}\right) q_{t+1}\right)=Q_{t}$ and $k_{i, t+1}\left(Q_{t+1}\left(r_{t+1}+1-\delta\right)-\right.$ $\left.Q_{t}\right)=0$. Hence, we get that

$$
\sum_{t=0}^{T}\left[Q_{t} c_{i, t}\right]+Q_{T} k_{i, T+1}+Q_{T} q_{T} h_{i, T+1}=\left(1-\delta+r_{0}\right) k_{i, 0}+\left(\left(1-\delta_{h}\right) q_{0}+r_{h, 0}\right) h_{i, 0}+\sum_{t=0}^{T} Q_{t} \pi_{i, t} .
$$

Since $\sum_{t \geq 0} Q_{t} \pi_{t}<\infty$, we obtain $\sum_{t \geq 0} Q_{t} \pi_{i, t}<\infty$, and so is $\sum_{t \geq 0} Q_{t} c_{i, t}$. As a consequence, there exists the limit $\lim _{t \rightarrow \infty} Q_{t}\left(k_{i, t+1}+q_{t} h_{i, t+1}\right)$ for any $i$.

Assume that $\lim _{t \rightarrow \infty} Q_{t}\left(K_{t+1}+q_{t} H_{t+1}\right)>0$, there exists $i$ such that $\lim _{t \rightarrow \infty} Q_{t}\left(k_{i, t+1}+\right.$ $\left.q_{t} h_{i, t+1}\right)>0$. Hence there exists $t_{0}$ such that $k_{i, t+1}+q_{t} h_{i, t+1}>0$ for any $t \geq t_{0}$. According to Lemma 5, we have $\lim _{t \rightarrow \infty} Q_{t}\left(k_{i, t+1}+q_{t} h_{i, t+1}\right)=0$, a contradiction.

Proof of Lemma 7. According to the capital market clearing condition, we have $H_{t+1}=\left(1-\delta_{h}\right) H_{t}+G_{t}\left(H_{t}^{k}\right) \geq\left(1-\delta_{h}\right) H_{t}$ for any $t$. Therefore, we get that $H_{t+1} \geq$ $\left(1-\delta_{h}\right)^{t+1} H_{0}$. As a consequence, condition $\lim _{t \rightarrow \infty} Q_{t} H_{t+1} q_{t}=0$ implies that $\lim _{t \rightarrow \infty}(1-$ $\left.\delta_{h}\right)^{t} Q_{t} q_{t}=0$.

Proofs for Examples in Section 4.2. We will prove that the prices and allocations given in Section 4.2 constitute an equilibrium. To do so, we verify all conditions in Lemma 3. It is easy to see that all market clear.

We also see that, for any $t$,

$$
\begin{array}{r}
c_{A, 2 t}+K_{2 t+1}+q_{2 t} H_{2 t+1}=w \\
c_{A, 2 t+1}=\left(1-\delta+r_{2 t+1}\right) K_{2 t+1}+\left(q_{2 t+1}\left(1-\delta_{h}\right)+r_{h, 2 t+1}\right) H_{2 t+1} \\
c_{B, 2 t}=\left(1-\delta+r_{2 t}\right) K_{2 t}+\left(q_{2 t}\left(1-\delta_{h}\right)+r_{h, 2 t}\right) H_{2 t} \\
c_{B, 2 t+1}+K_{2 t+2}+q_{2 t+1} H_{2 t+2}=w .
\end{array}
$$

We now check the FOCs and transversality conditions.

We have

$$
\frac{\beta u^{\prime}\left(c_{A, 2 t+1}\right)}{u^{\prime}\left(c_{A, 2 t}\right)}=\frac{\beta c_{A, 2 t}}{c_{A, 2 t+1}}=\frac{\beta\left(w-K_{2 t+1}-q_{2 t} H_{2 t+1}\right)}{\left(1-\delta+r_{2 t+1}\right) K_{2 t+1}+\left(q_{2 t+1}\left(1-\delta_{h}\right)+r_{h, 2 t+1}\right) H_{2 t+1}} .
$$

By using (26) and (27), we have

$$
\frac{\beta u^{\prime}\left(c_{A, 2 t+1}\right)}{u^{\prime}\left(c_{A, 2 t}\right)}=\frac{q_{2 t}}{(1-\delta) q_{2 t+1}+r_{h, 2 t+1}}=\frac{1}{1-\delta+r_{2 t+1}} .
$$


We also have

$$
\begin{aligned}
& \frac{\beta u^{\prime}\left(c_{B, 2 t+1}\right)}{u^{\prime}\left(c_{B, 2 t}\right)}=\frac{\beta c_{B, 2 t}}{c_{B, 2 t+1}}=\frac{\beta\left(\left(1-\delta+r_{2 t}\right) K_{2 t}+\left(q_{2 t}\left(1-\delta_{h}\right)+r_{h, 2 t}\right) H_{2 t}\right)}{\left(w-K_{2 t+2}-q_{2 t} H_{2 t+2}\right)} \\
& =\beta\left(1-\delta+r_{2 t}\right) \frac{K_{2 t}+q_{2 t-1} H_{2 t}}{\left(w-K_{2 t+2}-q_{2 t} H_{2 t+2}\right)}=\beta\left(1-\delta+r_{2 t}\right) \frac{\beta \frac{w}{1+\beta}}{\frac{w}{1+\beta}}=\beta^{2}\left(1-\delta+r_{2 t}\right) .
\end{aligned}
$$

Since $\beta\left(1-\delta+a_{t}\right) \leq 1$ for any $t$, we obtain that

$$
\gamma_{2 t+1}=\frac{q_{2 t}}{\left(1-\delta_{h}\right) q_{2 t+1}+r_{h, 2 t+1}}=\frac{\beta u^{\prime}\left(c_{A, 2 t+1}\right)}{u^{\prime}\left(c_{A, 2 t}\right.} \geq \frac{\beta u^{\prime}\left(c_{B, 2 t+1}\right)}{u^{\prime}\left(c_{B, 2 t}\right)} .
$$

By using the same argument, we have

$$
\gamma_{2 t}=\frac{q_{2 t-1}}{\left(1-\delta_{h}\right) q_{2 t}+r_{h, 2 t}}=\frac{\beta u^{\prime}\left(c_{B, 2 t}\right)}{u^{\prime}\left(c_{B, 2 t-1}\right)} \geq \frac{\beta u^{\prime}\left(c_{A, 2 t}\right)}{u^{\prime}\left(c_{A, 2 t-1}\right)} .
$$

Transversality conditions are, for each $i=A, B$,

$$
\lim _{t \rightarrow \infty} \beta_{i}^{t} u_{i}^{\prime}\left(c_{i, t}\right) k_{i, t+1}=\lim _{t \rightarrow \infty} \beta_{i}^{t} u_{i}^{\prime}\left(c_{i, t}\right) q_{t} h_{i, t+1}=0 .
$$

\subsection{Proofs for Section 5}

Lemma 10. Consider the optimal growth problem

$$
\max _{(c, s)} \sum_{t=0}^{\infty} \beta^{t} \ln c_{t}
$$

subject to $c_{t}+s_{t+1} \leq A_{t} s_{t}$ and $c_{t}, s_{t} \geq 0$. The unique solution to this problem is given by $s_{t}=\beta^{t} A_{1} \cdots A_{t-1} A_{0} s_{0}$.

Proof. Indeed, the Euler condition $c_{t+1}=\beta A_{t+1} c_{t}$ jointly with the budget constraint becomes $s_{t+2}-\beta_{i} A_{t+1} s_{t+1}=A_{t+1}\left(s_{t+1}-\beta A_{t} s_{t}\right)$. Thus, a solution is given by $s_{t+1}=$ $\beta A_{t} s_{t}$. It is easy to verify the transversality condition $\lim _{t \rightarrow \infty} \beta^{t} u^{\prime}\left(c_{t}\right) s_{t+1}=0$.

By the concavity of the utility function, the solution is unique.

\subsection{Proof for Section 7}

Proof of Lemma 9. Let $\left(K_{t}^{\prime}, H_{t}^{\prime}, H_{t}^{c^{\prime}}, H_{t}^{k^{\prime}}\right)$ be a feasible production plan with $\left(K_{0}^{\prime}, H_{0}^{\prime}\right)=$ $\left(K_{0}, H_{0}\right)$

It is enough to prove that

$$
\sum_{t=0}^{T} Q_{t}\left(C_{t}-C_{t}^{\prime}\right) \geq-Q_{T} K_{T+1}-Q_{T} q_{T} H_{T+1}
$$


Denote $F_{K t}:=\frac{\partial F_{t}}{\partial K}\left(K_{t}, H_{t}^{c}\right)$ and $F_{H t}:=\frac{\partial F_{t}}{\partial H^{c}}\left(K_{t}, H_{t}^{c}\right)$. We have

$$
\begin{aligned}
& Q_{t}\left(C_{t}-C_{t}^{\prime}\right)=Q_{t}\left(C_{t}-C_{t}^{\prime}\right)+Q_{t} q_{t}\left(H_{t+1}-H_{t+1}^{\prime}\right)-Q_{t} q_{t}\left(H_{t+1}-H_{t+1}^{\prime}\right) \\
& =Q_{t}\left((1-\delta) K_{t}+F_{t}\left(K_{t}, H_{t}^{c}\right)-K_{t+1}-(1-\delta) K_{t}^{\prime}-F_{t}\left(K_{t}^{\prime}, H_{t}^{c^{\prime}}\right)+K_{t+1}^{\prime}\right)+ \\
& +Q_{t} q_{t}\left(G_{t}\left(H_{t}^{k}\right)-G_{t}\left(H_{t}^{k^{\prime}}\right)+(1-\delta)\left(H_{t}-H_{t}^{\prime}\right)\right)-Q_{t} q_{t}\left(H_{t+1}-H_{t+1}^{\prime}\right) \\
& \geq Q_{t}\left(\left(K_{t}-K_{t}^{\prime}\right) F_{K t}+\left(H_{t}^{c}-H_{t}^{c^{\prime}}\right) F_{H t}\right)+Q_{t}(1-\delta)\left(K_{t}-K_{t}^{\prime}\right)-Q_{t}\left(K_{t+1}-K_{t+1}^{\prime}\right) \\
& +Q_{t} q_{t} G_{t}^{\prime}\left(H_{t}^{k}\right)\left(H_{t}^{k}-H_{t}^{k^{\prime}}\right)+Q_{t} q_{t}(1-\delta)\left(H_{t}-H_{t}^{\prime}\right)-Q_{t} q_{t}\left(H_{t+1}-H_{t+1}^{\prime}\right) \\
& =Q_{t}\left(K_{t}-K_{t}^{\prime}\right) F_{K t}+Q_{t}(1-\delta)\left(K_{t}-K_{t}^{\prime}\right)-Q_{t}\left(K_{t+1}-K_{t+1}^{\prime}\right) \\
& +Q_{t}\left(H_{t}^{c}-H_{t}^{c^{\prime}}\right) F_{H t}+Q_{t} q_{t} G_{t}^{\prime}\left(H_{t}^{k}\right)\left(H_{t}^{k}-H_{t}^{k^{\prime}}\right)+Q_{t} q_{t}(1-\delta)\left(H_{t}-H_{t}^{\prime}\right)-Q_{t} q_{t}\left(H_{t+1}-H_{t+1}^{\prime}\right) \\
& \geq Q_{t}\left(r_{t}+1-\delta\right)\left(K_{t}-K_{t}^{\prime}\right)-Q_{t}\left(K_{t+1}-K_{t+1}^{\prime}\right)+ \\
& +Q_{t}\left(r_{h, t}+q_{t}(1-\delta)\right)\left(H_{t}-H_{t}^{\prime}\right)-Q_{t} q_{t}\left(H_{t+1}-H_{t+1}^{\prime}\right)
\end{aligned}
$$

Since $\left(K_{0}^{\prime}, H_{0}^{\prime}\right)=\left(K_{0}, H_{0}\right), Q_{t+1}\left(r_{h, t+1}+q_{t+1}(1-\delta)\right)=Q_{t} q_{t}, Q_{t+1}\left(r_{t+1}+1-\delta\right) \leq$ $Q_{t}$ and $K_{t+1}\left(Q_{t+1}\left(r_{t+1}+1-\delta\right)-Q_{t}\right)=0$, we have

$$
\begin{aligned}
& \sum_{t=0}^{T} Q_{t}\left(C_{t}-C_{t}^{\prime}\right) \\
& \geq \sum_{t=0}^{T-1}\left[\left(Q_{t+1}\left(r_{t+1}+1-\delta\right)-Q_{t}\right)\left(K_{t+1}-K_{t+1}^{\prime}\right)\right]-Q_{T} K_{T+1} \\
& +\sum_{t=0}^{T-1}\left[\left(Q_{t+1}\left(r_{h, t+1}+q_{t+1}(1-\delta)\right)-Q_{t} q_{t}\right)\left(H_{t+1}-H_{t+1}^{\prime}\right)\right]-Q_{T} q_{T} H_{T+1} \\
& =-Q_{T} K_{T+1}-Q_{T} q_{T} H_{T+1} .
\end{aligned}
$$

\section{References}

Alvarez F. and U.J. Jermann, Efficiency, equilibrium, and asset pricing with risk of default, Econometrica 70, 775-798 (2014).

Aoki K., Nakajima T. and Nikolov K., Safe asset shortages and asset price bubbles, Journal of Mathematical Economics 53, 165-174 (2014).

Araujo A., Pascoa M.R., Torres-Martinez J.P., Long-lived collateralized assets and bubbles, Journal of Mathematical Economics 47, p. 260-271 (2011).

Becker R., S. Bosi, C. Le Van and T. Seegmuller, On existence and bubbles of Ramsey equilibrium with borrowing constraints, Economic Theory 58, p. 329-353 (2015). 
Becker R.A., Dubey R.S., and Mitra T., On Ramsey equilibrium: capital ownership pattern and inefficiency, Economic Theory 55, p. 565-600, 2014.

Becker R. and T. Mitra, Efficient Ramsey equilibria, Macroeconomic Dynamics 16, 18-32 (2012).

Becker R. and E. Tsyganov, Ramsey Equilibrium in a Two-Sector Model with Heterogeneous Households, Journal of Economic Theory 105, 188-225 (2002).

Bloise G. and P. Reichlin, Asset prices, debt constraints and inefficiency, Journal of Economic Theory 146, 1520-1546 (2011).

Bosi S., Le Van C. and Pham N-S., Intertemporal equilibrium with production: bubbles and efficiency, CES working paper series (2014).

Brunnermeier M.K. and M. Oehmke, Bubbles, financial crises, and systemic risk, Handbook of the Economics of Finance, vol. 2 (2012).

Cass D., On capital overaccumulation in the aggregative, neoclassical model of economic growth: A complete characterization, Journal of Economic Theory 4, 200223 (1972).

Davila J., J.H. Hong, P. Krusell and J.-V. Ríos-Rull, Constrained efficiency in the neoclassical growth model with uninsurable idiosyncratic shocks, Econometrica 80, 2431-2467 (2012).

Farhi E. and Tirole J., Bubbly liquidity, Review of Economic Studies 79, 678-706 (2012)

Hirano T. and Yanagawa N., Asset bubbles, endogenous growth and financial frictions, Working Paper, University of Tokyo, 2013.

Huang, K. X. D., Werner J., Asset price bubbles in Arrow-Debreu and sequential equilibrium, Economic Theory 15, 253-278 (2000).

Kamihigashi T., A simple proof of the necessity of the transversality condition, Economic Theory 20, 427-433 (2002).

Kehoe T. and D. Levine, Debt Constrained Asset Markets, Review of Economic Studies 60, 865-888 (1993).

Kocherlakota, N. R., Bubbles and constraints on debt accumulation, Journal of Economic Theory, 57, 245 - 256 (1992).

Kocherlakota, N. R., Injecting rational bubbles, Journal of Economic Theory, 142, $218-232$ (2008).

Le Van C. and Pham N-S., Financial asset bubble with heterogeneous agents and endogenous borrowing constraints, mimeo, University Paris I Pantheon - Sorbonne (2014). 
Le Van C. and Pham N-S., Intertemporal equilibrium with financial asset and physical capital, Economic Theory, forthcoming (2015).

Lucas R. E., Asset prices in an exchange economy, Econometrica 46, 1429-1445 (1978).

Malinvaud E., Capital accumulation and efficient allocation of resources, Econometrica $21,233-268$ (1953).

Miao J., Introduction to economic theory of bubbles, Journal of Mathematical Economics 53, 130-136 (2014).

Miao J. and P. Wang, Bubbles and total factor productivity, American Economic Review: Papers and Proceedings 102, 82-87 (2012)

Miao J. and P. Wang, Bubbles and credit constraints, working paper, Boston University (2015).

Mitra T. and D. Ray, On the Phelps-Koopmans theorem, Journal of Economic Theory 147, 833-849 (2012).

Montrucchio, L., Cass transversality condition and sequential asset bubbles, Economic Theory, 24, 645-663 (2004).

Ramsey, F. P., A mathematical theory of saving, The Economic Journal, 38, pp. 543-559 (1928).

Santos, M. S., and Woodford, M. Rational asset pricing bubbles, Econometrica, 65, 19-57 (1997).

Solow R. M. A contribution to the theory of economic growth, The Quarterly Journal of Economics, 70, pp. 65-94 (1956).

Tirole J., On the possibility of speculation under rational expectations, Econometrica 50, 1163-1181 (1982).

Tirole J., Asset bubbles and overlapping generations, Econometrica 53, 1499-1528 (1985).

Ventura J. , Bubbles and capital flows, Journal of Economic Theory 147, 738-758 (2012).

Werner J., Rational asset pricing bubbles and debt constraints, Journal of Mathematical Economics 53, 145-152 (2014). 